\title{
BEHAVIOURAL CORRELATES OF ATYPICAL BRAIN MORPHOLOGY IN \\ INDIVIDUALS WITH HIGH LEVELS OF AUTISTIC-LIKE TRAITS
}

\author{
by \\ Simon Hill \\ A thesis submitted to \\ the Faculty of Graduate and Postdoctoral Affairs \\ in partial fulfillment of the requirements for the degree of \\ Master of Arts \\ in \\ Psychology
}

Carleton University

Ottawa, Canada

(C)2013 Simon Hill 


\begin{abstract}
The current study investigated whether atypical brain morphology extends to individuals in the normal population who are high in autistic-like traits. More specifically, it was hypothesised that autistic-like traits would be negatively correlated with hemispheric lateralization and communication. Additionally, males and individuals enrolled in mathematically intensive university programs were expected to display higher levels of autistic-like traits than females and individuals enrolled in less mathematically intensive programs. A sample of 130 university students completed the AQ questionnaire and three measures of brain morphology to assess autistic-like traits as well as hemispheric lateralization and communication. The results indicated that autistic-like traits in general were not associated with measures of hemispheric lateralization or communication. Only the university program in which the participants were enrolled yielded significant group differences on the AQ. It was concluded that the selected measures were not sensitive enough to detect atypical brain morphology differences in the present sample or that these differences do not exist in subclinical populations.
\end{abstract}




\section{Acknowledgements}

First, I would like to thank my supervisor Dr. Guy Lacroix. I cannot even begin to thank you enough for everything that you have done for me. When I arrived in your lab I had lost my confidence and was wondering about my future. Through your tutelage and encouragement I regained my strength and focus and learned how to become a better student and researcher. I am so fortunate to have had the honour of working with, and alongside such an amazing and brilliant man. I could not have done this without you.

I am also grateful for my committee. Dr. Anne Bowker - thank you for pushing me to think about my research objectively which has allowed me to become a more critical thinker. Additionally, a special thanks to Dr. Bowker for your support and advice through some difficult times. Dr. Cheryl Harasymchuk and Dr. George Pollard - thank you for contributing your time, knowledge, and expertise to the completion of this project.

Thank you to my psychophysics lab colleagues who have supported me. Georgina Faddoul - thank you for your dedication to this project, be it conversations about the theory, collection of the data, or general help along the way. Jordan, Mark, and Lisa thank you for helping me traverse my graduate student journey by providing me with insights and current research which contributed to my knowledge and success. To the rest of the lab, thank you for helping me practice and prepare for my defence.

Etelle Bourassa - thank you for being my utmost supporter and voice of reason. You were the first person I met when I arrived at Carleton, and you have been so caring and supportive through every step I have made. In my moments of despair, you always 
showed me the light. You go above and beyond every day, and all of us are so very lucky and fortunate to have you guiding us through our journeys.

Aileen - we met at the beginning of my journey, as you were progressing through your M.A. degree. I was able to watch as you blazed the trail that I was to follow, which alone would have made this endeavour easier. However, you also supported me in my moments of despair, and rejoiced with me in my moments of elation. Throughout this entire process you have been a constant partner. Thank you for your patience and understanding, and most of all for your love.

Finally, I would like to thank my family. Mom and Dad - without your love and support, through the darkest times of my life, none of this would have been possible. You have pushed and guided me every day of my life which has allowed me to become the person I am today. You gave me a strong work ethic and a sense of integrity that has been essential to the completion of this thesis. I could never have asked for two better people as role models. Sharon - I have looked up to you all my life. I have always known that you were proud of me, and never questioned your love and support. Your ongoing strength is a constant inspiration to me in times when I may have been lacking the courage and confidence to go on. 


\section{Table of Contents}

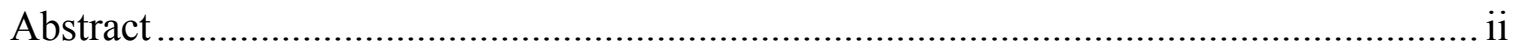

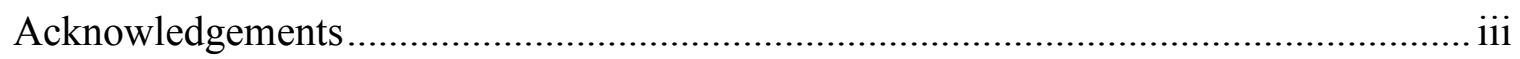

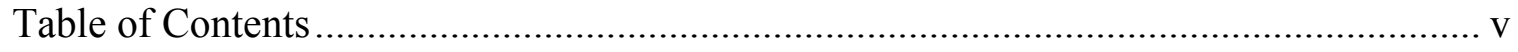

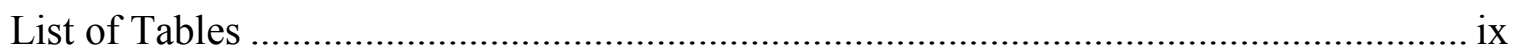

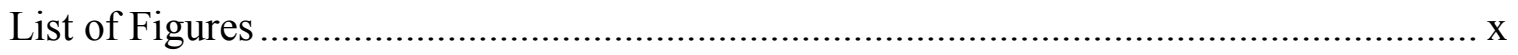

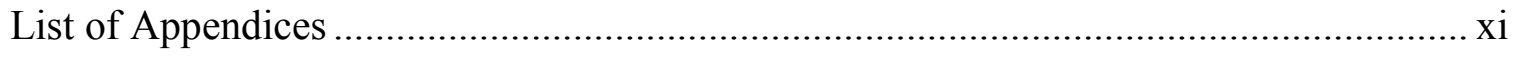

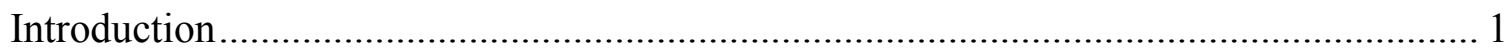

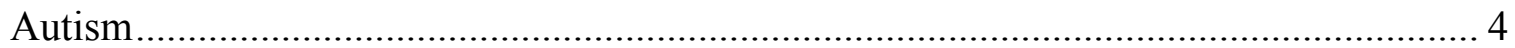

Autism Spectrum Disorders .......................................................................... 4

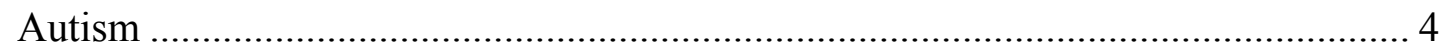

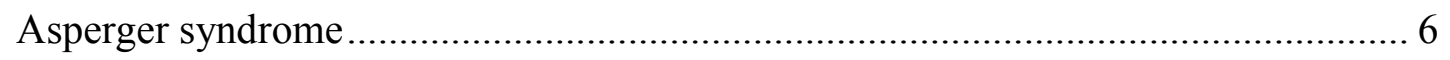

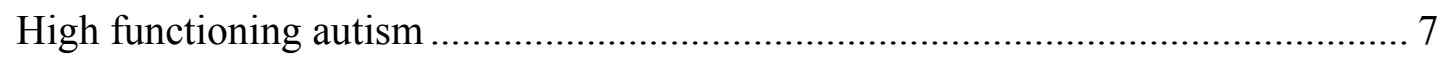

Theories of Autism ............................................................................................. 7

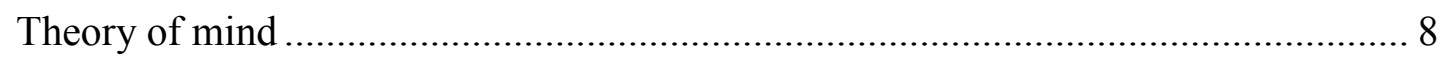

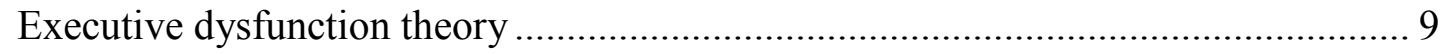

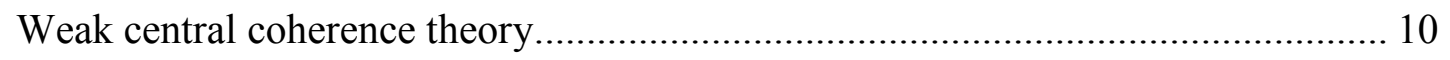

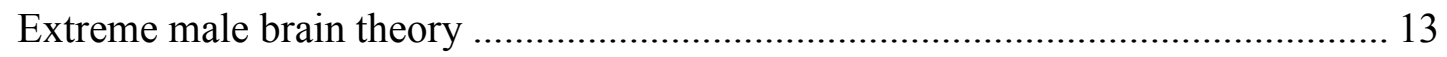

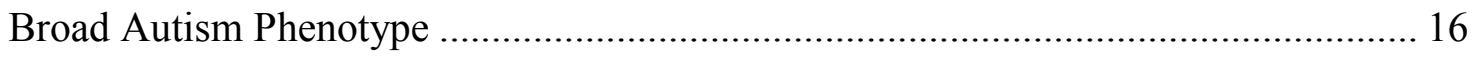

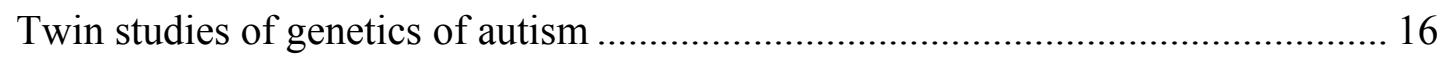

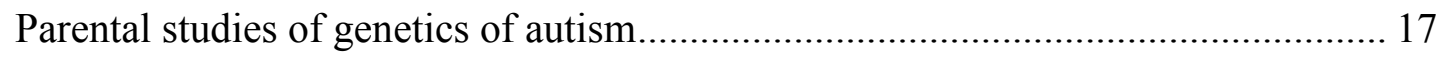

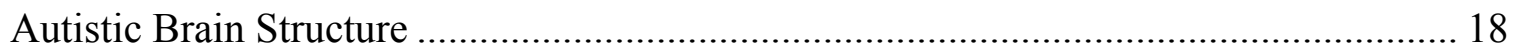

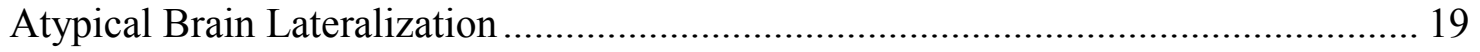




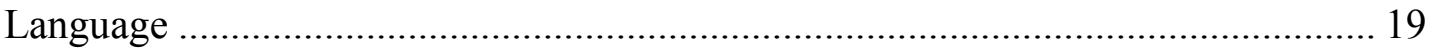

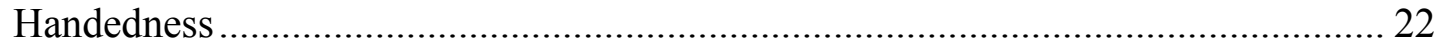

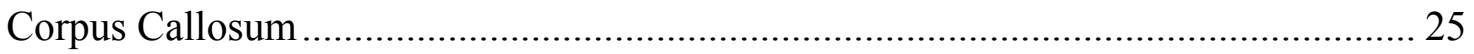

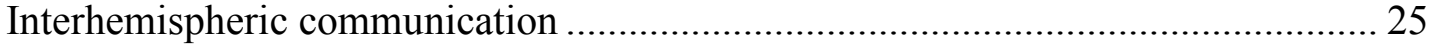

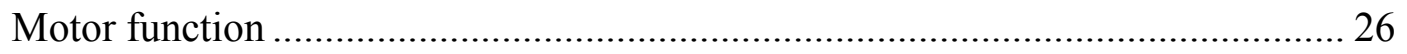

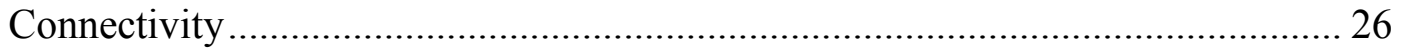

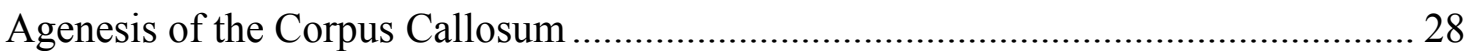

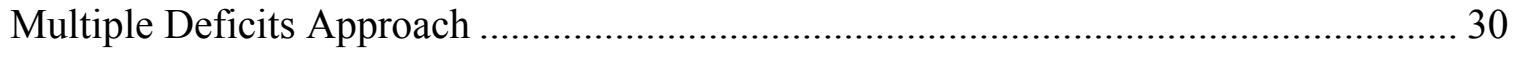

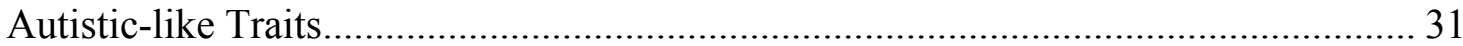

Autism-spectrum quotient questionnaire (AQ Questionnaire) ......................... 31

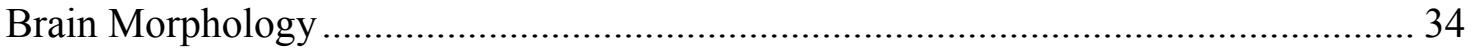

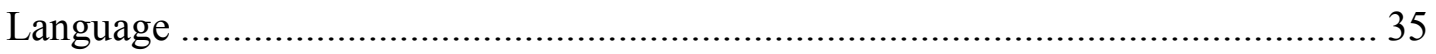

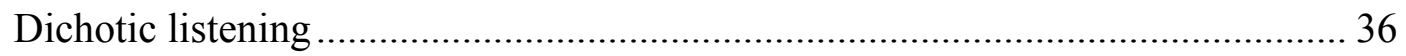

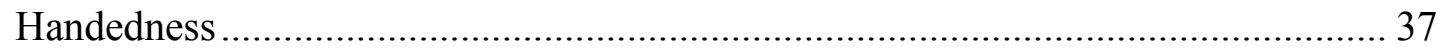

Waterloo Handedness Questionnaire ............................................................ 37

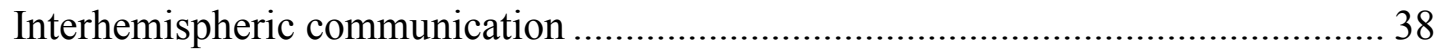

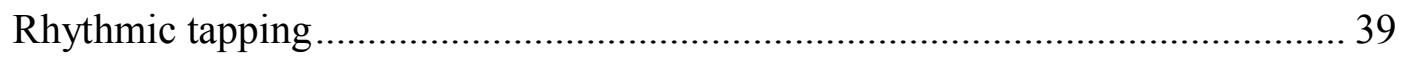

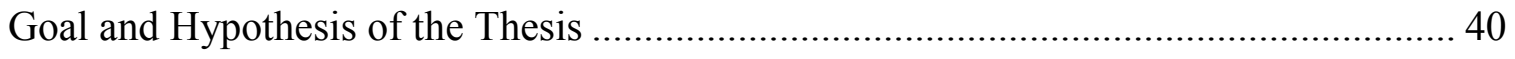

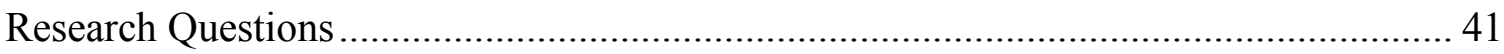

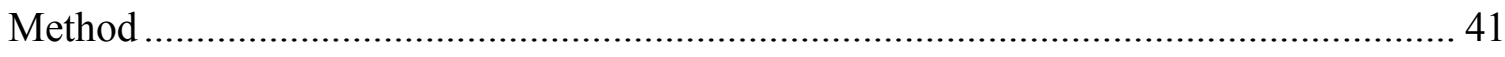

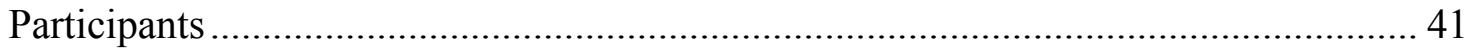

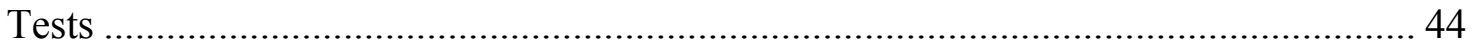

The Autism Quotient Questionnaire ................................................................... 44 
Bergen Dichotic Listening Test ............................................................................. 45

Waterloo Handedness Questionnaire.................................................................. 47

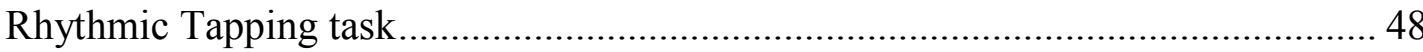

Additional Information Questionnaire................................................................... 50

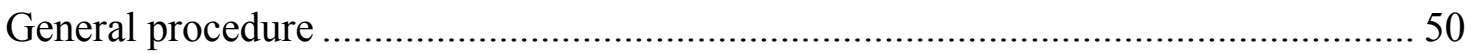

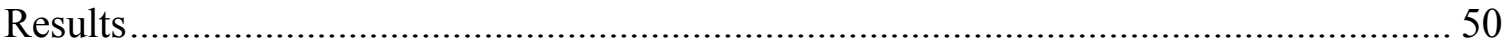

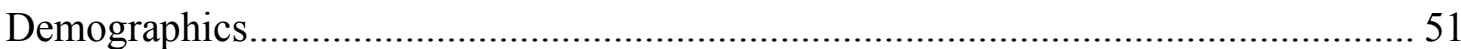

Measures of Autistic Traits, Dichotic Listening, Waterloo Handedness Questionnaire,

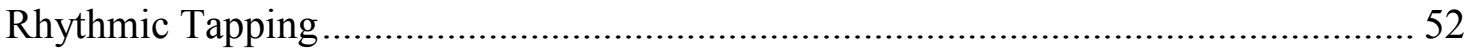

Correlations among Variables ............................................................................. 55

Distribution of AQ scores and internal consistency of a five-factor AQ .................. 58

Factor structure of the AQ based on Baron-Cohen et al. (2001) ............................... 59

Distribution of scores and internal consistency of a three-factor AQ ....................... 60

Factor structure of the revised AQ based on Austin (2005) ....................................... 61

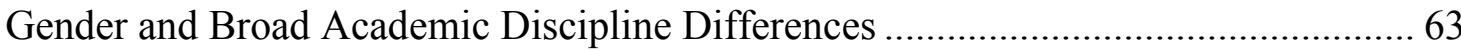

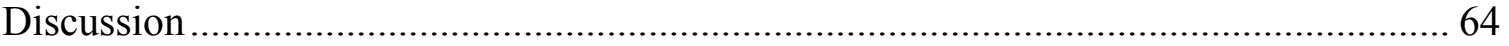

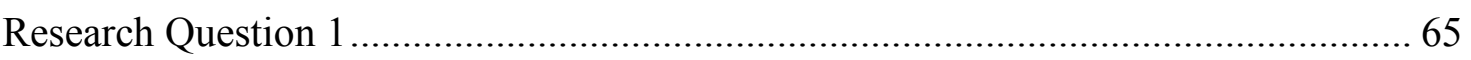

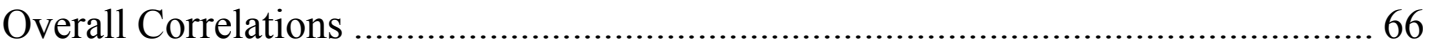

Correlation (WHQ to revised AQ communication) ................................................... 66

Correlation (Left hand tapping variability with AQ imagination) ............................6 67

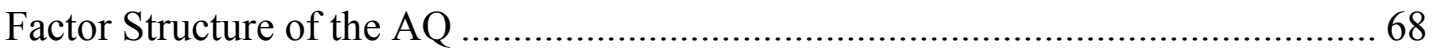

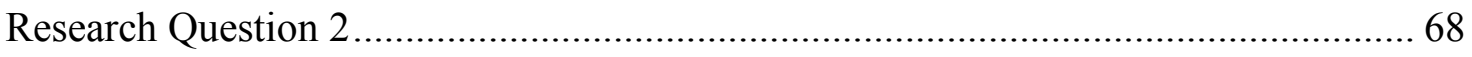

Gender differences in brain morphology and autistic-like traits .................................. 69 
Broad academic discipline group differences in brain morphology and autistic-like traits

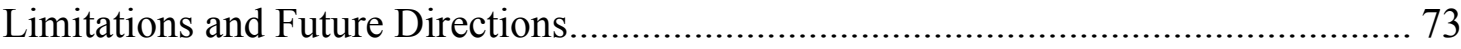

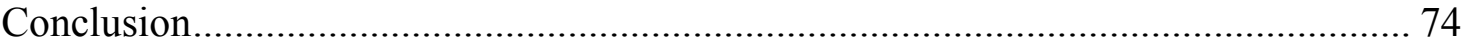

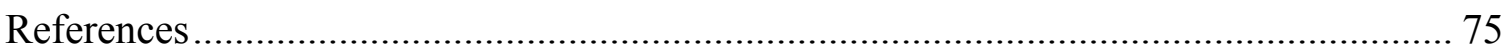

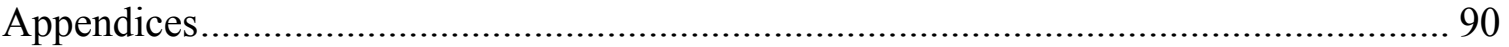




\section{List of Tables}

Table 1 Participants' gender and degree classified into three broad categories of academic disciplines: physical science; biological science; and social science and humanities

Table 2 Demographic information for Physical Science $(n=44)$, Biological Science $(n=64)$, and Social Science \& Humanities $(n=22)$

Table 3 Descriptive Statistics for the AQ, Dichotic Listening test, WHQ, and Rhythmic

Tapping test

Table 4 Correlations among autistic-like traits, brain lateralization, and

interhemispheric communication, and GPA 56

Table 5 Autism Quotient descriptive statistics and alphas 58

Table 6 Three-factor Autism Quotient descriptive statistics and alphas 61 


\section{List of Figures}

Figure 1. Scree plot for the Baron-Cohen 50-item Autism Quotient Questionnaire................... 60

Figure 2. Scree plot for the Austin 26-item Autism Quotient Questionnaire............................ 62

Figure 3. Mean AQ score collapsed across Academic Discipline Group with SE bars ............. 63 


\section{List of Appendices}

Appendix A: Autism Quotient Questionnaire...................................................................... 90

Appendix B: Bergen Dichotic Listening Test Score Sheet............................................... 92

Appendix C: Bergen Dichotic Listening Test Instructional Paragraph ................................. 93

Appendix D: Waterloo Handedness Questionnaire ......................................................... 94

Appendix E: Rhythmic Tapping Task Instructional Window .......................................... 95

Appendix F: Additional Information Questionnaire _....................................................... 96

Appendix G: Five-Factor AQ Item Loadings ................................................................ 97

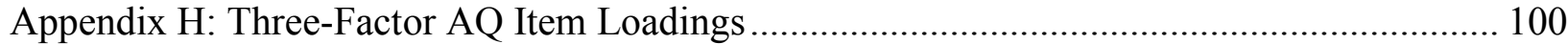




\section{Introduction}

It is not uncommon to come across individuals who appear to lack social skills. They may appear emotionless or disengaged; they may perseverate engaging in conversational topics despite other people's ostensible disinterest; and they may fail to abide by social conventions. These behaviours are typically viewed to be negative (Swaim \& Morgan, 2001) and they are often found to be unacceptable (Chambres, Bonin, \& Grenier, 2001; Harnum, Duffy \& Ferguson, 2007). Unfortunately, people's responses to these individuals' apparent lack of social skills is to ignore them, dismiss them, or even sometimes to respond to them with ridicule or hostility (Gray, 1993). These behaviours are characteristics of autism spectrum disorders.

Autism is a genetically inherited disorder characterised by deficits in communication, social reciprocity, and restricted, repetitive behaviours. When most people think of autism, they think of an extremely disabling condition where the individual is unable to function within society, and not necessarily of a socially awkward "science geek." Yet, the evidence has pointed to the existence of autistic-like traits in the general population (Constantino \& Todd, 2003, 2005), and even in the university population (Hurley, Losh, Parlier, Reznick, \& Piven, 2007). These individuals often excel in mathematics, science, and engineering (Baron-Cohen, Wheelwright, Skinner, Martin, \& Clubley, 2001), and they may be subsumed under the broad autism phenotype.

The broad autism phenotype suggests that autism is the result of a genetic vulnerability during brain development (Bailey et al., 1995; Bolton et al., 1994; Hurley et al., 2007). It makes a strong and testable prediction: there is a broad continuum of autistic-like traits within the general population. Autism represents one extreme of this 
continuum which is based on the severity of the core features associated with the disorder. As an individual moves further to the side of this continuum, the autistic deficits become less severe. Many of the dominant cognitive theories of autism (e.g., theory of mind; Baron-Cohen, Leslie, \& Frith, 1985, executive dysfunction; Ozonoff, Pennington, \& Rogers, 1991, weak central coherence; Frith \& Happe, 1994, extreme male brain; Baron-Cohen, 2002) also suggest that autism lies on a continuum. Moreover, each theory independently suggests that autistic symptomatology is heterogeneous, thus yielding many levels of severity. These theories further propose that many behavioural deficits related to autism (e.g., language processing, preferred handedness, and rhythmic tapping) may be associated with atypical hemispheric lateralization and reduced interhemispheric communication (Chura et al., 2010; Corriveau \& Goswami, 2009; Escalante-Mead, Minshew, \& Sweeney, 2003; Hauck \& Dewey, 2001; Isenhower et al., 2012; Keary et al., 2009; Mostofsky et al., 2009; Soper et al., 1986; Vidal et al., 2005). Although there is a bevy of research suggesting that autistic-like traits may vary along a continuum in the general population, empirical support for this idea is sparse.

A major obstacle toward establishing a continuum of autistic-like traits in the general population is that the behavioural measures commonly used with autistic individuals may not be sensitive enough to detect finer distinctions within a broader autistic phenotype (Ozonoff, Rogers, Farnham, \& Pennington, 1993; Tager-Flusberg, 2004). It can be argued that this has led to mixed results in much of the literature (Gerdts \& Bernier, 2011). However, measures of brain laterality (e.g., Dichotic Listening Test; Hugdahl, 2009, and Waterloo Handedness Questionnaire; Steenhuis, Bryden, Schwartz, \& Lawson, 1990), and interhemispheric communication (e.g., the Rhythmic Tapping 
task; Pitre, 2006) have been established to detect differences in the general population, thus making them potentially suitable for individuals with broad autism phenotype. Assessing the connection of the behavioural correlates of atypical hemispheric lateralization and reduced interhemispheric communication with the level of autistic-like traits within the general population would thus provide empirical support for the view that autistic-like traits lay on a continuum. The goal of this thesis was to pursue this line of research.

Based on previous findings (Escalante-Mead et al., 2003; Klimkeit \& Bradshaw, 2006), I hypothesized that reduced brain lateralization and interhemispheric communication assessed with behavioural correlate measures would be related to increases in autistic-like traits in a sample of undergraduates. In support of this central idea, the introduction to the thesis is organized as follows. First, a review of the autism spectrum disorders and associated deficits will be presented to highlight how the categorization of the disorders is contingent on the severity of symptoms. Then, current cognitive theories of autism will be discussed, emphasizing the strengths and limitations of each. Third, information regarding the genetic basis and inheritance of autistic-like traits will be provided, with a focus on how it contributes to both the continuum view and the expression of an autistic phenotype within the general population. Fourth, an overview of the autistic brain structure will be provided discussing how atypical language, handedness lateralization, and poor interhemispheric communication within this population are associated with the core deficits of the disorder. Lastly, a multiple deficits approach of autistic research will be discussed. I will argue that there is a need for measures of autistic-like traits and behavioural correlates appropriate for usage in the 
general population. Specifically, an overview of the Autism Quotient Questionnaire, the Dichotic Listening Test, Waterloo Handedness Questionnaire, and Rhythmic Tapping task will be presented.

\section{Autism}

Autism is a disorder characterized by three core features: impairments in the development of reciprocal social interaction skills, impaired communication skills, and the presence of stereotyped behaviour, interests, and activities (American Psychiatric Association, Diagnostic and statistical manual of mental disorders ( $4^{\text {th }}$ ed., text rev.), 2000). Impairments are abnormal with regard to the developmental level or the mental age of the individual, and are often associated with some degree of mental handicap.

\section{Autism Spectrum Disorders}

The autism spectrum spans over a variety of disorders which fall under the Pervasive Developmental Disorders category ( $4^{\text {th }}$ ed., text rev.; DSM-IV-TR, American Psychological Association, 2000). Autism, Asperger's syndrome, and High Functioning Autism are all subsumed by this category, but vary in the severity of impairment. Each disorder has marked differences in the degree and presentation of symptoms from each of the core features.

Autism. Autism is the most extreme disorder in the autism spectrum because impairments are serious and prolonged. Social interaction impairments can include difficulties in nonverbal behaviours (e.g., eye-to-eye contact and facial expressions) which result in the failure to develop peer relationships. The desire for social relationships may be present in older autistic individuals, but there is a lack of understanding of the conventions of social interaction. Specifically, there is a lack of 
seeking to share in the enjoyment, interests, and achievements of others. This desire for social interaction can be further hindered by poor awareness of others' needs.

Impairments in communication may result in delayed or absent development of speech, and those who do develop speech have an impaired ability to initiate or sustain a conversation. Speech may also display abnormal pitch, intonation, and rhythm, and the grammatical structures often include stereotyped and repetitive use of words or phrases. There may also be marked deficits in the social imitation of others. Finally, individuals with autism may have difficulties in following simple directions.

In addition to the marked deficits in social interaction and communication, autistic individuals exhibit restricted, repetitive, and stereotypic patterns of behaviour, interests, and activities. They have stereotyped body movements (e.g., clapping hands, rocking, or swaying), and abnormal body postures (e.g., odd hand movements). They may display an unusually strong need to adhere to specific routines or rituals, and may become distressed when changes occur.

In most cases, autistic individuals are also diagnosed with a mild to profound mental handicap ( $4^{\text {th }}$ ed., text rev.; DSM-IV-TR, American Psychological Association, 2000). Autistic individuals have an unusually high threshold for pain, they are oversensitive to sounds or touch, and they can have a fascination with certain stimuli. A clinical diagnosis for autism includes a total of six specific impairments related to the three core features of the disorder. Of these six impairments, there is a minimum requirement that two of them are deficits in social interaction, one a restricted, repetitive, and stereotyped pattern of behaviour, interest, and activity, and one deficit in communication. 
Asperger syndrome. Asperger's syndrome is similar to autism but its defining impairments are generally less severe and less problematic for these individuals' daily functioning. Impairments with regard to social interaction are comparable to those found in autism. A major difference in social interaction between the two disorders, however, is that Asperger's syndrome is typically defined by a lack of social reciprocity resulting in a one-sided conversation, whereas autism is defined by a social and emotional indifference to the conversation topic.

The restricted, repetitive patterns of behaviour, interests and activities feature is also present in Asperger's syndrome. Nevertheless, unlike autism, the major behavioural marker is a preoccupation with a particular topic or interest about which the individual has gathered a great deal of information. Interests and activities are also often pursued with a great intensity to the exclusion of other activities.

The major difference between autism and Asperger's syndrome is that the latter disorder does not entail any clinically significant delays in early language. Nevertheless, at older ages, individuals with Asperger's syndrome may display unusual speech in terms of the preoccupation with certain topics which results in a wordy conversation style.

In contrast to autism, no significant mental handicap is associated with Asperger's syndrome. A clinical diagnosis of Asperger's syndrome must include a total of three specific impairments (two in social interaction, and one in restricted, repetitive patterns of behaviours, interests and activities); (4 ${ }^{\text {th }}$ ed., text rev.; DSM-IV-TR, American Psychological Association, 2000). Furthermore, there can be no clinically significant delay in language or cognitive development. 
High functioning autism. Impairments in high functioning autism are less severe than either autism or Asperger's syndrome. High functioning autistic individuals do not meet the criteria for a full diagnosis of autism due to late age onset and failure to meet the symptom thresholds (e.g., milder delays that do not significantly impact important areas of functioning). Moreover, there is no significant mental handicap or cognitive development associated with high functioning autism.

Finally, it must be noted that within each of the three autism spectrum disorders, there is an increased prevalence rate for males. Specifically, males are four to five times more likely to be diagnosed with autism or high functioning autism, and at least five times more likely to be diagnosed with Asperger's syndrome $\left(4^{\text {th }}\right.$ ed., text rev.; DSM- $I V$ TR, American Psychological Association, 2000).

\section{Theories of Autism}

Autism is characterized by heterogeneity in skills and impairments in each of the three core features, which results in a wide variety and severity of symptoms and the ensuing categories of the autistic spectrum disorders. For this reason, it has been difficult to establish a comprehensive theory of autism because none are able to provide an explanation for the triad of deficits. The three dominant cognitive theories of Autism theory of mind (Baron-Cohen et al., 1985), executive dysfunctioning (Ozonoff et al., 1991), and weak central coherence (Frith \& Happe, 1994) - attempt to provide an explanatory link between autistic behavioural deficits and abnormal information processing. Each theory seems to shed some light on a specific piece of the autism puzzle. A fourth theory, the extreme male brain theory (Baron-Cohen, 2002), attempts to 
explain the deficits in autism by discussing the three cognitive theories in relation to genetic anomalies. In the following sections, I will discuss each of these theories in turn.

Theory of mind. The theory of mind starts from the principle that mental states need to be inferred because they are impossible to directly observe. Thus, the ability to understand other people's thoughts, beliefs and desires is the result of a complex cognitive mechanism (Baron-Cohen, 1988). The theory of mind account of autism is based on the inability of individuals with autism to ascribe mental states to themselves and others. Consequently, they are unable to take others' mental states into account when they engage in social interactions (Rajendran \& Mitchell, 2007). This inability results in a lack of eye contact, atypical facial expressions, communication impairments, and delayed or absent speech development. Support for an autistic deficit in theory of mind has come from research using false belief tasks (i.e., tests of the ability to think recursively about others' intentional states; Baron-Cohen, 1988; Baron-Cohen et al., 1985), the Strange Stories test which measures the ability to infer different motivations behind a lie (Happe, 1994), and the Eyes Task which assesses the ability to recognize emotions from the eyes (Baron-Cohen, Jolliffe, Mortimore, \& Robertson, 1997). Studies show that, on each of these tasks, autistic participants consistently perform poorer than controls.

Nevertheless, despite the fact that autistic individuals tend to do more poorly than controls, they do not show outright failure (Rajendran \& Mitchell, 2007). Specifically, some autistic individuals are able to pass both first and second order false belief tests. This leads to a major criticism against the theory of mind in relation to autism: the more advanced tests (i.e., Strange Stories and Eyes Task) seem to have been developed solely in response to inconsistent data. A second criticism of the theory of mind is that deficits 
have been found in individuals diagnosed with mental retardation, and therefore are not unique to the autistic disorder (Levy, 2007). Theory of mind deficits might be a reflection of low IQ because this is common in both disorders, rather than specific to autism. A final criticism of the theory of mind is that it is unable to address many autistic individuals' restricted, repetitive, and stereotypic patterns of behaviour. Any comprehensive theory of autism would undoubtedly need to address the full triad of deficits associated with it. Thus, the theory of mind cannot be understood as the singular explanation for autistic deficits.

Executive dysfunction theory. The executive dysfunction theory attempts to address the major weakness of the theory of mind by explaining the restricted, repetitive, and stereotypic patterns of behaviour displayed by individuals with autism. Specifically, it has been noticed that autistic symptoms (e.g., the need for sameness, the difficulty in switching attention, and lack of impulse control) are similar to those associated with a specific type of prefrontal cortex injury (Lopez, Lincoln, Ozonoff, \& Lai, 2005).

The most comprehensive definition of the theory suggests that executive dysfunction pertains to autistic individuals' inability to "...to maintain an appropriate problem-solving set for attainment of a future goal. It includes behaviours such as planning; impulse control inhibition of prepotent but irrelevant responses; set maintenance; organized search; and flexibility of thought and action" (Ozonoff et al., 1991, p. 1083). Executive dysfunction is measured using three distinct constructs: inhibition, intentionality, and executive memory (Ozonoff \& Jensen, 1999; Ozonoff, Strayer, McMahon, \& Filloux, 1994). Support for the executive functioning theory has come from research using the Stroop Test to assess difficulties inhibiting a predominant 
response (Ozonoff \& Jensen, 1999), the Tower of Hanoi which measures the ability to handle embedded rules in goal directed behaviours (Bennetto, Pennington, \& Rogers, 1996), and the Wisconsin Card Sorting Test which assesses attention switching (Pascualvaca, Fantie, Papageorgiou, \& Mirsky, 1998).

Despite the evidence of impaired inhibition, intentionality, and executive memory in autism, the research has produced mixed support for the executive dysfunction theory. Rajendran and Mitchell (2007) have argued that this is due mainly to increased task demands of executive functioning tests (e.g., attention and focus), along with the heterogeneous nature of the symptoms in the autistic disorder. A more troublesome criticism of the executive dysfunction theory, considering its initial conception, is that it cannot explain all the restricted, repetitive behaviours and interests of autistic individuals. Lopez et al. (2005) found that both intact (i.e., working memory, verbal and nonverbal fluency) and impaired (i.e., executive memory and intentionality) cognitive processes predicted the same amount of variance in restricted, repetitive behaviours and interests. These results indicated that an executive deficits or dysfunction model is insufficient to account for all restrictive, repetitive symptoms. A final criticism of the executive dysfunction theory is that it lacks an explanation of the social deficits in the autistic domain (Rajendran \& Mitchell, 2007).

Weak central coherence theory. The weak central coherence theory provides a bridge between the theory of mind and the executive dysfunction theories; it strives to explain both the social and non-social features of autism (Rajendran \& Mitchell, 2007). Furthermore, it does not assume that autism is best defined by a cognitive deficit or 
dysfunction. Rather, the weak central coherence theory presents autism as an alternative cognitive style.

The weak central coherence hypothesis was inspired by Gestalt principles of perceptual organization (Frith \& Happe, 1994). More specifically, it postulates that autistic individuals have difficulties processing information holistically. It proposes that they process information in a fragmented fashion, which results in the superiority of local, feature-based processing rather than a deficit in global processing. For example, where people would typically see a chair, an autistic individual might instead see legs, a seat, and armrests (Parritz \& Troy, 2011). From the stand point of this theory, although autistic individuals can process information holistically, they display a preference for unique individual elements.

Support for the weak central coherence theory has come from different sources. For instance, some research has shown that autistic individuals display enhanced performance on embedded figures and block design tasks (Shah \& Frith, 1993). Superior local processing results in locating an embedded figure faster and quicker recognition of the unique elements required to create a holistic image. Other research has shown better performance on perceptual learning and conjunctive visual search tasks which indicate reduced generalization of stimuli similarities (Plaisted, 2001; Plaisted, O’Riordan, \& Baron-Cohen, 1998a; 1998b). Specifically, faster performance in finding the target stimuli which shares one feature in common with a variety of distractor stimuli, indicates better discrimination of unique elements and reduced generalization of common features. Finally, research has indicated interference from local processing on global processing using divided and selective attention tasks (Plaisted, Swettenham, \& Rees, 1999; 
Rinehart, Bradshaw, Moss, Brereton, \& Tonge, 2000). A significantly slower reaction time in identifying a global stimuli and a non-significant reaction time difference for a local stimuli in comparison to controls, indicates greater interference of local processing for autistic individuals.

Nevertheless, support for the weak central coherence theory is far from consensus. One major criticism of the theory is that it explains the cognitive style of two disorders (i.e., Williams syndrome and Autism) using the same cognitive constructs, despite empirical evidence to the contrary (Martin \& McDonald, 2003). First, these two disorders have well-established differences in the social language domain: Autistic individuals display severe deficits in this domain, while individuals who have Williams Syndrome do not (Martin \& McDonald, 2003). Secondly, individuals with these disorders perform differently on Block Design tasks which are commonly used to indicate weak central coherence. Despite this fact, the theory attributes both types of performance to a local processing bias. Specifically, autistic individuals are thought to have a local processing bias because of a superior performance on the Block Design, reflecting an ability to find the unique elements in the design (Frith \& Happe, 1994). However, Williams' syndrome individuals are similarly believed to have a local processing bias because of an inferior performance on the Block Design, reflecting and inability to see the overall configuration (Karmiloff-Smith, Klima, Bellugi, Grant, \& Baron-Cohen, 1995). Clearly, the same mechanism cannot be responsible for both disorders.

In closing this review of the cognitive theories of autism, one conclusion emerges: The heterogeneity of the deficits associated with autism appears to account for the field's inability to present a unified theory that explains all aspects of the disorder. Nonetheless, 
each cognitive theory does adequately explain certain core aspects of the condition.

These observations strongly suggest that the theories are not mutually exclusive although they do focus on different etiological aspects of the disorder. Moreover, what these three theories lack is an overarching theoretical framework; one that can explain autism's three core deficits in addition to other well-known findings such as genetic heritability and gender differences. Many more males are diagnosed with autism than females (Hartley \& Sikora, 2009). Furthermore, genetic inheritability is associated with autism (Folstein \& Rutter, 1977), as well as behavioural correlates for handedness (Medland, Duffy, et al., 2009; Medland, Wright, et al., 1997) and language lateralization (Bryden, 1975). A theory that attempts to offer such a framework is the Extreme male brain theory.

Extreme male brain theory. There are slight brain structural and functional differences between males and females that impact behaviour (Cosgrove, Mazure, \& Staley, 2007). The extreme male brain theory (Baron-Cohen \& Hammer, 1997) contends that males have a more systemizing brain which drives them to search for and analyse the rules that underlie behaviour. Conversely, females have a more empathising brain that drives to identify with another person's emotions and thoughts, and to respond to them appropriately. Baron-Cohen's (2002) findings that, in the general population, females outperform males on tests of empathising (e.g., theory of mind, empathy quotient, eyes test, complex facial expressions, eye contact, and language development), while males outperform females on systemising tests and tasks (e.g., attention to detail, tests of intuitive physics, systemizing quotient, obsessions with closed systems such as computers, and preferences for rule-based, structured, factual information) support this theory. When Baron-Cohen (2002) compared empathising and systemizing test scores of 
autistic individuals to control male participants, he found that they scored higher on tests of systemizing, and lower on tests of empathising. Hence, Baron-Cohen (2002; BaronCohen et al., 2011) argues that the extreme male brain theory can simultaneously explain all the core aspects of autism: impoverished empathising leads to poor communication and social skills while enhanced systemizing leads to an exaggerated attention to detail and repetitive behaviour.

In addition, the extreme male brain theory can explain the sex differences in autism's prevalence rates. Because males already have a more systemizing brain, it takes a slighter shift on the empathising-systemising continuum for them to develop the autistic brain type. Alternatively, it takes a larger shift for females who have a more empathising brain. Additionally, Baron-Cohen (2002) and Baron-Cohen et al. (2011) emphasized that genetics was involved in empathising-systemising development. Baron-Cohen (2002) indicated that on a test of the broad autism phenotype (i.e., a set of personality and language characteristics that reflect a phenotypic expression of a genetic liability to autism; Hurley et al., 2007, p. 1679), high-functioning autistic individuals scored higher than neurotypical males, who in turn scored higher than females. Furthermore, they found that there was a higher rate of autism in the families of individuals who had strong mathematics, physics or engineering skills. Genetic inheritance of extreme male brain is believed to be regulated by fetal testosterone, as an early development of puberty was correlated with increased levels of testosterone in autistic males.

Baron-Cohen et al. (2011) further indicated that genes on the $\mathrm{X}$ and $\mathrm{Y}$ chromosomes could be regulated by fetal testosterone. Moreover, increases in fetal testosterone have been linked to increased rightward asymmetry of the thickness of a 
subsection of the corpus callosum: the isthmus (Chura et al., 2010). The isthmus projects to the posterior parietal and superior temporal cortices, and is believed to be the primary mechanism for lateralization of the human brain. The extreme development of systemising in the autistic brain can explain the deficits found in the cognitive theories (Baron-Cohen, 2002). Specifically, autistic individuals perform poorer on tests of theory of mind because this task requires empathising. The need for sameness mentioned in the executive dysfunction theory is explained as the autistic individuals' attempt to impose predictability on the unpredictable social world. The tantrums and repetitiveness are an outward attempt to control the actions of others. Lastly, the superior local processing noted by the weak central coherence theory is an autistic individual focusing on local details in an attempt to analyse the variables which govern the behaviour or system.

The previous sections examined autism spectrum disorders and current theories of autism. Next, a review of the literature on the genetic inheritance of autistic-like traits and an overview of autistic brain structure will be presented. The idea that autistic-like traits lie on a continuum implies that mild expressions of autistic traits should be found in the general population. Indicators of such traits would include all combinations of the three core features (impairment in reciprocal social interactions, impaired communication skills, and restricted, repetitive, and stereotyped patterns of behaviour, interests, and activities), at lower severity levels of impairment. The lower severity levels of autistic impairments may be key to understanding how autistic-like traits are transmitted to subsequent generations and is the basis of the broad autistic phenotype (Folstein \& Rutter, 1977). 


\section{Broad Autism Phenotype}

Broad autism phenotype is a rapidly evolving theory regarding the genetic foundation of autism. It is based on a set of personality and language characteristics that reflect the phenotypic expression of a genetic inheritance of autism (Hurley et al., 2007). More specifically, broad autism phenotype theory argues that there are phenotypic expressions of social interaction and communication deficits, as well as repetitive stereotyped behaviours in non-autistic relatives of autistic individuals. Primary support for the theory comes from twin studies that indicate a stronger autistic link between monozygotic siblings than between dizygotic siblings.

Twin studies of genetics of autism. In a study of 21 twin pairs (10 dizygotic, 11 monozygotic), Folstein and Rutter (1977) compared autistic characteristics in pairs of same sex twins for which at least one twin was autistic. The concordance rate for autism in dizygotic twins was $0 \%$ whereas it was $36 \%$ for monozygotic twins. Given these results, further investigation was warranted. If autism represented a narrow expression of a broader spectrum, then Folstein and Rutter (1977) argued that it was important to examine milder manifestations of the core features (deficits in communication, impairments of reciprocal social interaction, and repetitive or stereotyped behaviours) of the disability in the non-autistic twins. Although seven monozygotic, non-autistic twins were found to be discordant for autism, five still showed some form of cognitive deficit in speech or language. In contrast, only one of the ten dizygotic twins demonstrated similar deficits. Combining both concordant and discordant twins, nine out of eleven monozygotic twins and one out of ten dizygotic twins showed some form of cognitive disability. 
In a follow-up experiment, Bailey et al. (1995) obtained similar findings in a study of 28 twin pairs (11 dizygotic, 17 monozygotic). The results demonstrated a $0 \%$ concordance rate for autism in dizygotic twins in contrast to a $69 \%$ concordance rate among monozygotic twins. Additionally, $88 \%$ of monozygotic twins compared to only $9 \%$ of dizygotic twins both showed some kind of cognitive deficit. These preliminary results suggested that genetics play at least a partial role in the development of autism. The findings of these studies, however, can only be generalized to siblings of autistic individuals. They do not address generational transmission of autistic expression.

Parental studies of genetics of autism. To examine familial similarities in autistic characteristics, Bolton et al. (1994) examined both the parents and siblings of autistic individuals in comparison to a group of parents and siblings of individuals with Down syndrome. The purpose for this particular comparison group was to control for the effects of having a handicapping disorder within the family and the possible environmental effects (e.g., reduced psychosocial development and functioning due to atypical social interaction with a disabled relative) on the first degree relatives. Once again, the three core features of autism (deficits in communication, impairments of reciprocal social interaction, and repetitive or stereotyped behaviours) were assessed. The results showed that stereotyped behaviours were twice as common in the relatives of autistic individuals and that communication and social deficits were more than three times more common. Parental autistic symptoms were milder, sometimes only showing one of the core features than those of the siblings.

Constantino and Todd (2005) also assessed the broad autism phenotype using the Social Responsiveness Scale, which they administered to both siblings and parents of 
autistic female twins. The scale measures the ability of participants to engage in appropriate reciprocal social interaction, with higher scores representing impairment. Both siblings and parents who scored high on the Social Responsiveness Scale also displayed higher levels of autistic-like traits. Sibling scores were higher on average than parent scores and they also increased as the combination of parental scores increased.

In summary, both twin and familial studies indicate that autism has a strong genetic basis. The broad autism phenotype both supports the notion that autism has a strong genetic basis and that deficits lie on a continuum. Furthermore, the continuum appears to revolve around the severity of the core triad deficits. The genetic abnormalities that cause the disorder also create a distinctly autistic brain structure (Baron-Cohen et al., 2011). Specifically, the autistic brain has atypical lateralization and a smaller corpus callosum subsection (Chura et al., 2010).

\section{Autistic Brain Structure}

Chura et al.'s (2010) indication that increased fetal testosterone correlates with a smaller isthmus presents a possible mechanism for the development of the autistic brain. As mentioned earlier, the isthmus is believed to be the precursor to the development of typical brain laterality, and is known to project to (and thus communicate with) the posterior parietal and superior temporal cortices. Specific autistic anatomical differences in brain lateralization have been primarily supported by the findings of reduced language (Lindell, 2006; Lindell, Notice, \& Withers, 2009; Minshew, Goldstein, \& Siegel, 1995; Whitehouse \& Bishop, 2008), and handedness laterality (Escalante-Mead et al., 2003; Soper et al., 1986; Yeo, Gangestad, Thoma, Shaw, \& Repa, 1997). Reduced interhemispheric communication has been primarily supported by indications of poor 
motor functioning (Hauck \& Dewey, 2001; Isenhower et al., 2012) and unusual cortical connectivity (Corriveau \& Goswami, 2009; Keary et al., 2009; Mostofsky et al., 2009; Vidal et al., 2005). These brain structural differences may underlie autistic behavioural impairments in the core features of the disorder.

\section{Atypical Brain Lateralization}

Language. Unusual language lateralization may be the biological cause of impairments in communication and reciprocal social interaction of autistic individuals. It would affect both verbal and non-verbal communication abilities which are essential in interpreting social cues. Hemispheric differences in language processing have been the focus of extensive research in developmental disorders such as autism for years. Research has focused on narrowing down specific elements of language that are affected in autistic individuals.

Minshew et al. (1995) sought to examine the nature of speech and language impairment in autistic individuals. They assessed the language of 62 high-functioning autistic individuals and 50 age matched controls using a battery of tests assessing complex information processing (e.g., verbal problem solving, inference making, and ability to interpret complex written material) and basic procedural language abilities. The results indicated that high-functioning autistic individuals had poorer performances on tests of comprehension and interpretive language abilities, without showing any notable differences in procedural language abilities. An important finding also indicated that IQ was not significantly different for the two groups. This result indicated that highfunctioning autistic individuals' intelligence is similar to that of control participants despite having poorer language ability. Minshew et al.'s study led to the conclusion that 
the language deficits in high-functioning autism tend to involve comprehension and interpretation.

In a related study, the connection between language lateralization and level of autistic-like traits was assessed in a university population. Lindell et al. (2009) tested 51 university students using the Autism Quotient Questionnaire and a visual word or nonword recognition test. Words presented in the visual field corresponding to the dominant hemisphere for language would have a shorter distance to travel to the processing area, and thus would be recognized faster. Alternatively, words presented in the visual field corresponding to the non-dominant hemisphere would have a further distance to travel for processing, and thus would be recognized slower. Hence, a larger difference in reaction times between the two visual fields would signify hemispheric dominance for language, whereas smaller differences would be indicative of bilateral activation. The results demonstrated a relationship between autistic traits and language lateralization. As the number of autistic-like traits increased, reaction time differences between right and left visual presentation of words and non-words decreased. This result suggests that individuals with more autistic traits have decreased brain asymmetry for language. Although the evidence suggests unusual language development and laterality in the autistic population, there are a variety of other developmental disorders that also show unusual brain lateralization (Klimkeit \& Bradshaw, 2006). To understand how the atypical brain development of autistic individuals contributes to the language deficits specific to the disorder, research was needed to establish how language deficits in other disorders differed from those found in autism. 
To accomplish this goal, Whitehouse and Bishop (2008) tracked cerebral blood velocity in autism spectrum and selective language impairment individuals while they were performing a test of phonemic expression (i.e., the silent construction of words beginning with a particular letter). Both autism spectrum patients and selective language impaired participants showed unusual brain lateralization compared to controls. Nevertheless, the degree of lateralization in the autism spectrum group was not significantly different from that of the selective language groups. A subsequent analysis on the two developmental groups revealed that although both showed bilateral activation, the language impaired individuals had a greater proportion of right activation in comparison to autistic individuals. Although language deficits and unusual brain lateralization are common to both autism and selective language impairment, they constitute two distinct groups because of the further shift to right hemisphere usage in language impaired individuals. Whitehouse and Bishop's research indicates that language in autism does not seem to shift to the right hemisphere. Rather, it tends to be more bilateral.

The research that has been reviewed up to this point has established decreased language lateralization in autistic individuals. In the normal population, language lateralization is also closely connected to handedness. Specifically, George (2010) found that only 5 percent of right-handers did not have language abilities lateralized to the left hemisphere of the brain. However, in 30 percent of left-handers, language abilities were either bi-hemispheric or lateralized to the right hemisphere of the brain. This indicates that handedness is another measure of brain laterality, and because odd hand movements are a known symptom of autism, it might show a similar atypical lateralization as 
language. This notion is supported by research indicating increased levels of left handedness within autism (Soper et al., 1986). If research were to find that both handedness and language are similarly compromised in autistic individuals while displaying distinct patterns of atypical brain laterality, then the etiological cause of autism might be further clarified.

Handedness. Abnormalities in autistic handedness may suggest a biological cause for the restricted, repetitive, and stereotyped pattern of behaviours, and more specifically, the odd hand movements associated with autism. Within the normal population, handedness tends to favour left-hemisphere control. However, within the autistic literature, the discovery of higher prevalence rates of left and ambiguous handedness (i.e., no defined handedness; Soper et al., 1986) indicates potential right- or bi-lateral hemispheric control.

Soper et al. (1986) initially sought to clarify the accuracy of reports of increased left-handedness in the autistic population. Additionally, they wanted to determine if autistic handedness subgroups would differ in terms of cognitive functioning. Two groups of autistic individuals (48 lower- and 31 higher-functioning) were assessed for handedness and intellectual functioning using the Hand Preference Demonstration Test, and the Wechsler Intelligence Scale for Children-Revised or the Stanford-Binet (for lower- and higher-functioning individuals respectively). The results indicated that 22 percent of the individuals in the study were left-handed, which was significantly more than the 10 percent reported in the normal population (Hardyck \& Petrinovich, 1977). This corroborated the reports of increased left handedness in autistic individuals. However, the results also revealed three handedness subgroups: right-, left-, and mixed- 
handedness. This previously unrecognized third subgroup of mixed-handed individuals represented 36 percent of the sample. This group of participants provided inconsistent answers to the same items on repeated administrations of the Hand Preference Demonstration Test. Soper et al. defined these individuals as displaying ambiguous handedness, which also suggested bilateral control. Further analyses revealed that individuals with mixed-handedness had reduced cognitive functioning and lower IQ scores compared to individuals with right- and left-handed preference. The indication that the ambiguous handedness subgroup displayed reduced cognitive functioning and lower IQ scores supports the theory that decreased brain lateralization is associated with more severe autistic symptoms. However, Soper et al. did not establish whether handedness was a distinct feature of autistic lateralization, which is important for distinguishing whether different lateralization measures tap different autistic deficits.

To assess whether handedness lateralization was distinct from language lateralization in autism, Escalante-Mead et al. (2003) compared the handedness of two autistic subgroups that differed in developmental language disturbances (i.e., abnormal early language and normal early language) to controls. Handedness was assessed using the Edinburgh Handedness Inventory (Oldfield, 1971). The two autistic subgroups showed lower rates of right handedness than the normal population as expected. The two autistic subgroups' handedness did not differ from each other, however, indicating that it was not related to early language development. This further indicated that language and handedness lateralization measures were tapping unique elements of autistic deficits. Although it has been established that autistic individuals have reduced or reversed 
handedness lateralization, explanations for this phenomenon are still under debate (see Annett, 1998; Yeo et al., 1997).

The best explanation for handedness differences within autism, which is in concordance with the other etiological theories, is Yeo et al.'s (1997) developmental instability theory. Yeo et al. propose that instability during fetal development creates an imprecise phenotypic expression of the normal left-hemisphere genetic plan. The developmental instability theory suggests that prenatal complications create abnormal physical features and observable variations of normal symmetric physical features (e.g., ear length) in autistic individuals, which reflects atypical brain development. Yeo et al. examined the relationship between the amount of developmental instability and handedness in a university population. The number of developmental instabilities for each participant was collected using the minor physical anomalies checklist and various physical indicators of fluctuating asymmetry (e.g., ear length and width). Participants were then given a battery of tests assessing handedness, language, cognitive performance, and perception of common facial expressions. The number of developmental instability markers was negatively correlated with handedness and language lateralization, perception of facial feature, and cognitive abilities.

Developmental instability may be regulated by the same system that creates abnormal handedness and language lateralization: fetal testosterone. Increases in developmental instability markers could be correlated with increases in fetal testosterone. This in turn creates atypical lateralization of handedness within the autistic population. This would also explain why males are at an increased risk for developmental instability; they have higher testosterone levels from the onset of development. 
Atypical lateralization of language and handedness in the autistic population supports both the extreme male brain theory and the involvement of fetal testosterone. Both language and handedness also appear to contribute uniquely to autistic deficits. As Chura et al. (2010) indicated, reduced interhemispheric communication in the form of a smaller isthmus is believed to be the precursor to atypical lateralization. This suggests that communication impairments and restricted, repetitive motor functions and behaviours could be mediated by interhemispheric communication because both hemispheres are needed to perform complex cognitive skills (e.g., language) and motor movement (e.g., bimanual hand activities).

\section{Corpus Callosum}

Interhemispheric communication. Reduced interhemispheric communication may lead to poor transmission of neural signals between the hemispheres which are required for complex cognitive skills and motor movements. Interhemispheric communication pertains to issues of connectivity in brain structures responsible for the transmission of neural signals between the two hemispheres (Fournier, Hass, Naik, Lodha, \& Cauraugh, 2010). Although interhemispheric structural deficits have been noted in the cerebellum (Abrahams \& Geschwind, 2008; Schroeder, Desrocher, Bebko, \& Cappadocia, 2010) and the amygdale (Levy, 2007) of autistic individuals, the corpus callosum is responsible for the transmission of higher order cognitive processes such as false belief tasks in theory of mind (Brown \& Paul, 2000). A deficient or poorly functioning corpus callosum could prevent signals responsible for normal communication, social interaction, and motor functions from reaching the opposite hemisphere, and could be an underlying cause of the core features of autism. Bimanual 
hand coordination is a task that requires interhemispheric communication because the brain areas for using each hand are located in the opposing hemisphere.

Motor function. Isenhower et al. (2012) assessed the motor functioning of seven autistic children on a bimanual hand coordination task. Participants were directed to tap a drum with both hands at the same time then again by alternating each hand at their own pace after a brief demonstration. The results demonstrated that autistic individuals were poorer than controls at staying in rhythm regardless of the task, indicating reduced motor coordination overall. When participants were required to tap in alternation, autistic individuals reverted to simultaneously tapping the drum with both hands more often than controls. Isenhower et al. explained their results by hypothesizing that they may be indicative of a connectivity issues in the corpus callosum.

Although these results are informative, Isenhower et al. (2012) did not report the handedness of the participants or have a large enough sample to test for possible gender differences. Without the report of handedness, it is hard to establish whether the children in the sample were truly representative of the autistic population. Because of the noted gender discrepancy in the autistic population, it would have been advantageous to discover if there were any motor coordination differences between the sexes, which also would have provided additional support for the representativeness and generalizability of the findings. Despite the limitations of the study, the results do provide preliminary support for motor deficits within the autistic population which could be symptomatic of underlying connectivity issues.

Connectivity. To examine whether connectivity issues underlie motor function deficits in autism, Mostofsky et al. (2009) used fMRI to study the brain activity of high 
functioning autistic children and controls while they performed a finger tapping task. A pre-screening measure assessing motor functioning indicated that autistic children had poor motor performance in comparison to the controls. The results from the fMRI indicated that autistic individuals had reduced brain activation in both hemispheres and had poorer connectivity between those brain regions which were activated. Mostofsky et al. theorized that autistic individuals had an increase in local connections and a decrease in connections between more distant brain regions. This results in greater local processing, but poorer integration of multiple brain regions.

Increased local connections and greater local processing is believed to underlie the increased brain size of autistic individuals (Anderson et al., 2011). Moreover, poor integration of multiple brain regions represents the deficits in understanding social interactions, communication, and coordination of body parts (e.g., hands or fingers). Although Mostofsky et al.'s (2009) study can account for the lower overall brain activation observed in the autistic children and provides support for Just et al.'s (2004, 2007) proposal of cortical under-connectivity, it does not examine any physical differences (e.g., length or volume) of the corpus callosum. Thus, the results do not explicitly provide support of reduced connectivity between the hemispheres.

Keary et al. (2009) provided empirical support of reduced hemispheric connectivity by assessing corpus callosal volume differences in a group of high functioning autistic individuals and control participants. Participants completed four neuropsychological tests which required interhemispheric communication. fMRI results indicated that a variety of brain regions including the anterior portion of the corpus callosum were smaller in individuals with autism. A correlation between the volume of 
the corpus callosum and performance on the neuropsychological tests was observed. Specifically, decreases in the size of the corpus callosum resulted in increased negative performances on each of the neurological tests. Taken together with observed motor deficits and decreased brain activation, the smaller volume of the corpus callosum in autistic individuals is consistent with the theory of poor interhemispheric connectivity.

Both brain laterality and interhemispheric communication develop abnormally in autistic individuals. Moreover, these mechanisms also appear to explain the observable deficits associated with the disorder. In addition, it has been established that autistic-like traits are found in the general population, which indicates that autism-like traits lie on a continuum. Consequently, it is reasonable to suggest that autistic behavioural correlates of atypical brain laterality and interhemispheric communication might similarly lie on a continuum. One way to examine this possibility is to observe autistic-like deficits in a disorder with similar brain structure anomalies. Agenesis of the corpus callosum is such a disorder.

\section{Agenesis of the Corpus Callosum}

Agenesis of the corpus callosum is a disorder that causes the corpus callosum to be absent from birth. This results in similar brain structural anomalies (e.g., corpus callosum deficits; Paul et al., 2003, and atypical brain lateralization; Sauerwein \& Lassonde, 1994) to those found in autistic individuals. However, autistic disruptions in other areas which facilitate interhemispheric communication, (e.g., cerebellum and amygdale) are unaffected in agenesis of the corpus callosum. From this view, individuals with agenesis of the corpus callosum have milder impairment of interhemispheric communication than autism due to proper development of distal connection pathways 
running through the amygdale and cerebellum. Since agenesis of the corpus callosum represents a milder version of the brain structural anomalies thought to underlie autism, individuals with this disorder may similarly display autistic-like deficits. Specifically, it would be expected that individuals with agenesis of the corpus callosum would show milder autistic-like deficits due to mild autistic brain structural anomalies

Evidence from research assessing behavioural problems (Badarunddin et al., 2007), psychosocial (Brown \& Paul, 2000; Sauerwein \& Lassonde, 1994), and communication deficits (Brown et al., 2005; Brown, Symington et al., 2005; Paul et al., 2003) in the agenesis of the corpus callosum deficits indicates that individuals with this disorder do display autistic-like symptoms. Furthermore, Badarunddin et al. noted that of the three core features of autism, only social impairments were of equal severity between the two disorders. Individuals with agenesis of the corpus callosum did display milder communication impairments than found in autism, but there was no evidence of restricted, repetitive, behaviours.

This preliminary comparison between disorders with similar brain structure deficits does suggest that the brain mechanisms which cause autistic deficits may lie on a continuum. Individuals with agenesis of the corpus callosum show milder brain structural anomalies and autistic symptoms compared to those diagnosed with autism. In fact, many of the cognitive and diagnostic tests used to identify and research autism (e.g., Wisconsin Card Sorting Test and the Child Behaviour Checklist) are similarly used on agenesis of the corpus callosum individuals, and show milder forms of the same deficits (Brown \& Paul, 2000). This further strengthens the argument that autistic brain structural anomalies lie on a continuum based on severity. Because autistic-like traits are observable in the 
general population, autistic brain mechanisms may also be found in the general population. To date, only one study has assessed a brain mechanism in conjuncture with autistic-like traits in the general population (Lindell et al., 2009). These researchers, however, only looked at the connection between language lateralization and autistic-like traits.

The research that I have reviewed up to this point indicates that brain physiology (i.e., atypical lateralization and interhemispheric communication) may underlie the core features of autism (reciprocal social impairment, communication impairments, and restrictive, repetitive, and stereotyped behaviours, interests, and activities). Furthermore, both autistic behavioural deficits and cerebral morphology appear to lie on a continuum which is based on severity (i.e., more severe autistic brain structural anomalies results in greater severity of deficits). Finally, it has been proposed that because autistic behavioural deficits can be found in the general population, the same might be true of autistic cerebral morphology. In the next section, I will present a multiple deficits approach to researching behavioural correlates of autistic brain structure in connection to autistic-like traits in the non-autistic population.

\section{Multiple Deficits Approach}

The existence of autistic-like traits in non-autistic family members has led to the creation of specialized measures for the broad autistic phenotype because the traditional clinical tools could not distinguish these individuals from the rest of the general population. Broader phenotypic individuals may only display one or two of the core features of autism in a milder form making them much more difficult to detect. A well- 
established measure of the broad autism phenotype is the Autism-spectrum Quotient questionnaire (Baron-Cohen et al., 2001).

\section{Autistic-like Traits}

Autism-spectrum quotient questionnaire (AQ Questionnaire). Baron-Cohen et al. (2001) developed the Autism Quotient Questionnaire to assess the broader autistic phenotype in the general population given that existing instruments (e.g., Autism Diagnostic Observation Schedule, Autism Diagnostic Interview, and Childhood Autism Rating Scale) either took too long to administer or required professional administration. Their objective was to develop a brief, self-administered instrument, which could identify the degree to which a person within the general population might have autistic-like traits. The Autism Quotient consists of 50 questions (10 each relating to 5 different areas: social skill, attention switching, attention to detail, communication, and imagination), scored on a 4-point Likert scale with forced answers (definitely agree, slightly agree, slightly disagree, definitely disagree). Scores range from $0-50$ and higher scores indicate higher levels of autistic-like traits.

Test-retest reliability was verified by testing a subset of participants twice, which resulted in no significant differences between the scores while maintaining a strong correlation $(r=.70)$. Cronbach's alpha coefficients for each of the 5 areas were calculated $($ communication $=.65$, social $=.77$, imagination $=.65$, local details $=.63$, and attention switching $=.63$ ) indicating that the Autism Quotient had a fair degree of internal consistency. Validation of the Autism Quotient was established by comparing three groups (high functioning autism, general population control group, university control group). The main result was that the high functioning autistic group had higher 
overall scores (and area scores) than the control groups. Further analyses revealed that males scored significantly higher than females in the general population. These results confirmed the Autism Quotient Questionnaire's ability to detect autistic-like traits and gender differences in a normal population. Group differences were not related to IQ or SES, however.

In addition to gender differences, significant differences among broad classes of academic disciplines were also found. Specifically, students enrolled in mathematics obtained higher AQ scores than those in other academic disciplines including engineering and the physical sciences. Nevertheless, this latter group of students scored higher than those in medicine and biology. Finally, students who studied the humanities obtained the lowest AQ scores. Hence, this set of analyses established that the AQ questionnaire can also distinguish university students from different academic disciplines.

The Autism Quotient was designed to capture the amount of autistic-like traits of individuals using scores which ranged from 0 to 50. Baron-Cohen et al. (2001) determined that scores above 32 would distinguish individuals with the broad autism phenotype from those who would possibly qualify for a clinical diagnosis of autism. This was established on the basis of the finding that $80 \%$ of the high functioning autism group scored above 32 compared to only $2 \%$ of the controls. To further confirm that the cut-off was diagnostic of autism, Baron-Cohen et al. (2001) requested a clinical evaluation for the eleven university control students who scored above 32. It was discovered that seven students met all four criteria needed for a diagnosis of high functioning autism while the other four met three. 
Despite good reliability and validity, and a strong rationale for the cut-off point to separate possible clinical and broad autistic phenotype levels of autistic traits, the Autism Quotient has nevertheless been the target of some criticism. Specifically, Ketelaars et al. (2008) brought into question the replicability and cross-cultural applicability of the measure. Partial support for this position comes from the inability to find a gender difference in a US undergraduate population (Hurst, Mitchell, Kimbrel, Kwapil, \& Nelson-Gray, 2007). However, Austin (2005) was able to replicate Baron-Cohen et al.'s (2001) results using an undergraduate sample, and Bishop et al. (2004) were able to replicate the Autism Quotient gender differences using the parents of autistic and control children as participants. Furthermore, Hoekstra, Bartels, Cath, and Boomsma (2008) were even able find to similar gender differences among a university population using a Dutch translated version of the Autism Quotient. Thus, the latter three studies appear to indicate that Autism Quotient does produce replicable and cross-culturally applicable results.

Nevertheless, Baron-Cohen et al.'s (2001) AQ factor structure has been found to be much harder to replicate than the gender differences. For instance, Hoeskstra, Bartels, Cath, and Boomsma (2008) suggested that the AQ had two underlying factors, whereas Austin (2005) and Hurst et al. (2007) favoured three. Stewart and Austin (2009) suggested there were four factors, and Kloosterman, Keefer, Kelley, Summerfeldt, and Parker (2011) favoured five. It should be noted that Kloosterman et al.'s five factors were different from Baron-Cohen et al.'s (2001) factors. Despite differences about the factor structure of the Autism Quotient, the reliability of the measure to detect group differences in autistic like traits was supported by all. 
Although research has provided support for the broad autism phenotype with regards to behavioural deficits, it does not explicitly connect deficits to brain structure. Additional support would be gained for the broad autism phenotype and the extreme male brain theory through the establishment of autistic-like cerebral morphology in this population. Specifically, it would be beneficial to note whether the Autism Quotient Questionnaire shows a relationship with behavioural correlates of atypical brain lateralization and interhemispheric communication.

\section{Brain Morphology}

As has already been discussed, two cerebral mechanisms that contribute to the autistic disorder are atypical brain lateralization and interhemispheric communication. Laterality measures of autistic language and handedness have been tailored to account for the deficits (e.g., impairments in communication and social reciprocity, and restricted, repetitive behaviours) and the limitations (e.g., low IQ, reduced cognitive skills, and lack of cooperation) of the population. Common language lateralization measures (e.g., the Detroit Tests of Learning Aptitude-2, The Token Test, Controlled Oral Word Association, and Animal Naming - Minshew et al., 1995), make use of pictures along with word generation and comprehension skills to test autistic individuals. Handedness is usually measured by questionnaires (e.g., Edinburgh Handedness Inventory questionnaire - Oldfield, 1971) which are very short (10 items) and cater to the short attention span of autistic individuals, while other behavioural measures (e.g., the Hand Preference Demonstration Test - Soper et al., 1986), simply require participants to pick up 8 different objects as they please. Interhemsipheric communication measures such as motor coordination have similarly been tailored to the autistic population by using simple 
tapping tasks (e.g., alternating taps between the hands - Isenhower et al., 2012; or tapping with and without a metronome - Corriveau \& Goswami, 2009). Although these specialized measures increase the reliability and validity of research in the autistic population, they reduce the power to detect autistic group differences at the lower end of the autism continuum (Ozonoff et al., 1993; Tager-Flushberg, 2004). Furthermore, many measures used in the autistic population were designed to detect delays in early development, not atypical development (Zwaigenbaum et al., 2007)

There are many measures currently in place to assess brain lateralization and interhemispheric communication within the general population which might be more suitable for use on individuals with the broad autistic phenotype. Standardized laterality measures such as a dichotic listening test, the Waterloo Handedness Questionnaire, and a complex rhythmic tapping test should bring to light differences in the behavioural correlates of atypical brain lateralization and interhemispheric communication within this population. These measures have been found to be reliable and valid for use in the normal population, and have sufficient sensitivity to detect fine distinctions between groups.

Language. A dichotic listening task may be used as a reliable measure of language lateralization. Kimura (1961a, 1961b) found that when individuals were presented with verbal stimuli simultaneously to both ears, they recalled information presented to the right ear more often and accurately than from the left ear. This result indicated that the brain hemisphere contralateral to the right ear (i.e., the left hemisphere) was dominant for language. This better recall for these stimuli was termed the right ear advantage for language lateralization. 
Prior to the right ear advantage finding, the Wada test was the accepted method for identification of hemispheric dominance for language, which involved carotid artery injections. However, the dichotic listening task provides a non-invasive alternative for language lateralization assessment which is comparable. It has good test-reliability (Hugdahl \& Hammar, 1997) and results are 92\% in agreement with the Wada test (Hugdahl, Carlsson, Uvebrant, \& Lundervold, 1997) indicating concurrent validity.

Dichotic listening. Rimol, Eichele, and Hugdahl (2006) suggested that the best dichotic listening paradigm to assess language lateralization was a forced-attention consonant-vowel syllable task. It includes three blocks of simultaneous presentation of 30 consonant-vowel combinations. The 30 pairs are built from combinations of six stop consonants (e. g., /b/, /d/, /g/, /p/, /k/, /t/) with a vowel (/a/) (36 total pairs minus 6 same set pairs). The 6 same set pairs are used to check if the participant has any difficulties in hearing stimuli correctly. The first block is a non-forced condition in which the experimenter does not direct the attention of the participant to a particular ear. In the second and third blocks, the experimenter asks participants to pay attention to right ear and left ear stimuli. These last two blocks are counter-balanced across participants and controlled for participant attentional biases (Hugdahl \& Andersson, 1986). Finally, all stimuli are presented at 70 decibels with no more than a 3 decibel difference between the ears (Hugdahl, Westerhausen, Alho, Medvedev, \& Hamalainen, 2008).

The forced-attention consonant-vowel syllable dichotic listening task has been found to be reliable and valid for a variety of age ranges and both genders (Hugdahl, Carlsson, \& Eichele, 2001), and it has been successfully used to test student populations 
(Hiscock, Inch, \& Kinsbourne, 1999; Saetrevik \& Hugdahl, 2007). Hence, it will be used in the current research.

Handedness. There are many different measures and ways to measure handedness as an indicator of brain lateralization. The abundance of measures in this field is connected to an argument about handedness as a theoretical construct. Two prevailing perspectives suggest that handedness should either be construed as hand performance (which can be established by comparing timing scores for each hand on a manual task) or hand preference (which can be determined by the answers to questions related to hand usage). Peters (1998) argued that both aspects are closely linked and that using both aspects is therefore redundant. Thus, for most handedness research performed in the general population, a measure of preference is sufficient.

Waterloo Handedness Questionnaire. The Waterloo Handedness Questionnaire measures both the direction (i.e., the right hand, the left hand or both) and the intensity of hand preference (Steenhuis et al., 1990). It consists of a 32-item questionnaire that uses both fine (e.g., pick up a screw) and gross (e.g., throw a spear) motor skills to sample a range of skilled (e.g., write name) and unskilled (e.g., pet an animal) activities.

Participants are asked to respond using a 5-point Likert scale with the following choices: "always use the left hand", "usually use the left hand", "use both hands equally", "usually use the right hand", and "always use the right hand." Average scores near the anchors indicate a strong hand preference whereas a central score indicates an absence of preference.

The Waterloo Handedness Questionnaire was originally validated with a sample of five hundred university students who were tested twice with an interval of at least two 
months (Steenhuis et al., 1990). The questionnaire displayed good test-retest reliability ( $r$ $=.88$ ). A principle components factor analysis of the questionnaire further revealed that it yielded two major factors relating to skilled and unskilled activities, and confirmed previous results (Steenhuis \& Bryden, 1989). An additional examination of the correlations of individual participant scores between the two administrations of the test revealed that three subjects had zero reliability scores, and were found to meet the definition of ambiguous handedness. This finding indicates the sensitivity of the measure to detect finer distinctions of the construct. The results from Steenhuis et al. (1990) are in line with previous research on factor structure (Steenhuis \& Bryden, 1989) and reliability of direction and intensity of hand preference (McMeekan \& Lishman, 1975), thus demonstrating concurrent validity. Peters (1998) asserted that the Waterloo Handedness Questionnaire length and response format represents the best trade-off between containing enough questions to make finer distinctions of handedness and minimizing the time requirement for participants to fill out the questionnaire. The ability of the Waterloo Handedness Questionnaire to detect individuals with ambiguous handedness would support Peters' claim. Additionally, Peters also suggests that a finger tapping test, which is not routinely practiced in conjuncture with handedness questionnaires, would also illuminate distinctions of handedness. Furthermore, finger tapping is commonly used in research assessing interhemispheric communication. The suggested use of both measures provides a link between behavioural correlates of atypical brain laterality and interhemispheric communication.

Interhemispheric communication. Finger tapping is a commonly used method of assessing interhemispheric communication within the normal population (Marion, 
Kilian, Naramor, \& Brown, 2003). However, there is debate as to the causal mechanism behind differences in finger tapping. Inaccurate perception of timing and a motor implementation delay are both perceived to be reasonable potential causal mechanisms (Price, Edgell, \& Kerns, 2012).

Price et al. (2012) assessed children with Asperger's syndrome against a control group for timing perception and timing production to clarify the issue. Participants were required to assess whether the interval between two auditory tones were longer or shorter than a previously presented interval, and then to tap in rhythm with a beat. The results indicated no difference in the timing perception. There was greater tapping variability in the Asperger's group, however. The results support the notion that variations in rhythmic tapping times indicate motor function deficits which underlie poor interhemispheric communication.

Rhythmic tapping. Rhythmic tapping is a measure of motor functioning and interhemispheric connectivity which requires the coordination of the limbs for accurate performance (Corriveau \& Goswami, 2009; Wittling, Schweiger, Rizhova, Vershinina, \& Starup, 2009). Wolff, Cohen, and Drake (1984) suggested that an asynchronous and isochronous tapping paradigm at a speed of 120 beats per minute is the best measure of motor performance and connectivity. This paradigm will be used in the current study. Asynchronous finger tapping involves different tapping sequences between the two hands (e.g., 3:1 ratio tapping requires one hand to tap to every third beat while the other hand taps on every beat). Isochronous tapping involves tapping to a beat with one hand alone or alternating tapping between the two hands. This paradigm thus involves a total of five finger tapping blocks of trials containing three isochronous blocks (each hand alone and 
alternating) and two asynchronous blocks (3:1 ratio beat with left tapping to every beat while the right taps to every third beat, then the reverse). Increased variability between successive taps with either hand represents reduced hemispheric communication.

Corriveau and Goswami (2009) used this paradigm on language impaired individuals and controls. Results indicated that language impaired participants had greater tapping variability across all trials in comparison to controls. Different asynchronous variability indicated that language impaired participants were not simply tapping a consistent beat outside the one being presented. Rhythmic tapping has good test-retest reliability and the replication of the independent result from Wolff et al. (1984) and Wolff et al. (1990) on reading disabled participants indicates high external validity.

\section{Goal and Hypothesis of the Thesis}

The goal of the current research was to determine if behavioural correlates of atypical brain lateralization and interhemispheric communication are associated with autistic-like traits in a sample of undergraduate participants. Based on the current research, it was hypothesised that a higher level of autistic-like traits would be negatively correlated to language and handedness lateralization, and interhemispheric communication. Furthermore, it was expected that more males than females, and more physical science than social science majors, would display higher levels of autistic-like traits. 


\section{Research Questions}

Research Question 1: Are behavioural correlates of brain lateralization and interhemispheric communication associated with scores on the AQ questionnaire?

Based on a review of the literature (Isenhower et al., 2012; Lindell et al., 2009; Soper et al., 1986), it was hypothesized that decreased language and handedness lateralization scores as well as deficits in interhemispheric communication would be correlated with higher Autism Quotient scores. Specifically, it was expected that decreases in dichotic listening and Waterloo Handedness Questionnaire scores along with increased rhythmic tapping variability would be correlated with higher scores on the Autism Quotient Questionnaire.

Research Question 2: Are distinct patterns of AQ questionnaire scores evident in the university population?

Based on Baron-Cohen et al. (2001) results, it was hypothesised that gender and area of study would display distinct patterns of autistic-like traits. Specifically, it was expected that males overall would display higher AQ questionnaire scores than females. Baron-Cohen et al. (2001) also found that a greater proportion of broad autistic phenotype individuals can be found in the physical sciences. Hence, it was expected that students in mathematics would display higher scores than those in engineering, biology, and science, who in turn would score higher than students in the social sciences.

\section{Method}

\section{Participants}

131 Carleton undergraduate university students from a variety of introductory courses and disciplines were recruited to participate in the study. A single participant was 
dropped due to an inability to follow instructions leaving the total sample at 130 participants. 86 participants were recruited from the first and second year Carleton University psychology participant pool. The remaining participants were not enrolled in a psychology program. They were recruited from in class announcements to first year biology, chemistry, math, and engineering classes; posters placed around campus; and emails forwarded through the biology, chemistry, and math departments. The participants received ten dollars or bonus course credit, and a one in sixty-five chance of winning an iPod as compensation for their participation.

Participants were sorted into one of three broad categories of academic disciplines: physical science; biological science; and social science and humanities. The number of female and male participants for each degree that were placed into these categories is shown in Table 1. Participant classification was based on a combination of the degree categorization structure from Baron-Cohen et al. (2001) and the hierarchy of scientific creativity from Simonton (2009). Both aforementioned classification systems had the same three tiered hierarchical structure with physical science at the top, biological science in the middle, and social science and humanities at the bottom. As such, the participants in the current study were placed into the lowest tier group from either classification system (e.g., Finance was considered a biological science by Simonton, but a social science by Baron-Cohen et al. (2001) and thus was classified as a social science in the current study). The resulting broad categories of academic disciplines represented a three tiered hierarchy based on both mathematics content and scientific creativity. 
Table 1

Participants' gender and degree classified into three broad categories of academic

disciplines: physical science; biological science; and social science and humanities

\begin{tabular}{|c|c|c|c|c|}
\hline \multirow[b]{2}{*}{ Broad Academic Discipline Group } & \multirow{2}{*}{$\begin{array}{l}\text { Carleton } \\
\text { Degree }\end{array}$} & \multicolumn{3}{|c|}{$N$} \\
\hline & & Male & Female & Total \\
\hline \multicolumn{5}{|l|}{ Physical Science } \\
\hline Biochemistry & $\mathrm{BSc}$ & 1 & 2 & 3 \\
\hline Chemistry & $\mathrm{BSc}$ & 3 & 3 & 6 \\
\hline Cognitive Science & $\mathrm{BCSc}$ & 1 & 3 & 4 \\
\hline Engineering & $\mathrm{BE}$ & 12 & 6 & 18 \\
\hline Integrated Science & $\mathrm{BSc}$ & 0 & 2 & 2 \\
\hline Math & $\mathrm{BSc}$ & 3 & 3 & 6 \\
\hline Physics & $\mathrm{BSc}$ & 2 & 0 & 2 \\
\hline Science & $\mathrm{BSc}$ & 0 & 3 & 3 \\
\hline Total & & 22 & 22 & 44 \\
\hline \multicolumn{5}{|l|}{ Biological Science } \\
\hline Biology & $\mathrm{BA}$ or $\mathrm{BSc}$ & 1 & 8 & 9 \\
\hline Computer Science & $\mathrm{BCS}$ & 1 & 1 & 2 \\
\hline Criminology & BA & 1 & 4 & 5 \\
\hline Linguistics & $\mathrm{BA}$ or $\mathrm{BSc}$ & 1 & 5 & 6 \\
\hline Neuroscience & $\mathrm{BSc}$ & 7 & 5 & 12 \\
\hline Political Science & $\mathrm{BA}$ & 0 & 1 & 1 \\
\hline Psychology & $\mathrm{BA}$ or $\mathrm{BSc}$ & 5 & 24 & 29 \\
\hline Total & & 16 & 48 & 64 \\
\hline \multicolumn{5}{|l|}{ Social Science \& Humanities } \\
\hline Accounting & BCom & 1 & 0 & 1 \\
\hline Business & BCom & 0 & 2 & 2 \\
\hline Child Studies & BA & 0 & 1 & 1 \\
\hline Commerce & BCom & 4 & 3 & 7 \\
\hline Communications & BA & 1 & 0 & 1 \\
\hline Film & BA & 1 & 0 & 1 \\
\hline Finance & BCom & 1 & 0 & 1 \\
\hline Journalism & BA & 0 & 1 & 1 \\
\hline Law & BA & 1 & 2 & 3 \\
\hline Music & $\mathrm{BA}$ & 0 & 1 & 1 \\
\hline Philosophy & $\mathrm{BA}$ & 0 & 1 & 1 \\
\hline Social Work & BSW & 0 & 1 & 1 \\
\hline Sociology & BA & 0 & 1 & 1 \\
\hline Total & & 9 & 13 & 22 \\
\hline Sample total & & 47 & 83 & 130 \\
\hline
\end{tabular}




\section{Tests}

The Autism Quotient Questionnaire (Baron-Cohen et al., 2001). The Autism Quotient Questionnaire was used to assess autistic-traits in the sample. The full questionnaire is provided in Appendix A. Participants responded to 50 items, using a 4point forced choice Likert scale (definitely agree, slightly agree, slightly disagree, definitely disagree). Ten items were allocated for each of the five domains (social skill, attention switching, attention to detail, communication, and imagination). Half the items were worded to produce "agree" and the other half to produce "disagree" responses in order to avoid response bias in either direction.

Scores were calculated using Baron-Cohen et al.’s (2001) system. “Definitely agree" or "slightly agree" responses to questions: $1,2,4,5,6,7,9,12,13,16,18,19,20$, $21,22,23,26,33,35,39,41,42,43,45$, and 46 each resulted in a score of one for those questions. "Definitely disagree" or "slightly disagree" responses to questions: $3,8,10$, $11,14,15,17,24,25,27,28,29,30,31,32,34,36,37,38,40,44,47,48,49$, and 50 each resulted in a score of one for those questions. This resulted in a score ranging from 0 to 50 with higher scores indicating increased levels of autistic-like traits. A score of 32 or more has been shown to be indicative of a potential autistic disorder.

The Autism Quotient reliability and validity were established using a variety of tests. First, the AQ's test-retest reliability was established using two administrations of the test on 840 university students. The two scores were not statistically different from each other $(p=.75)$ and were strongly correlated $(r=.70)$ (Baron-Cohen et al., 2001). Second, to assess the effectiveness of the AQ's self-report methodology, the families of 22 university students also completed a revised form of the questionnaire (i.e., 10 
subjective questions were removed). The informants' scores were only 2.8 points higher than the self-report scores, thus further establishing the AQ's validity. Third, the Cronbach's alphas for each of the five domains show that they each have reasonable internal consistency $($ social skill $=.77$, attention switching $=.67$, attention to detail $=.63$, communication $=.65$, and imagination $=.65)$. Moreover, the validation of the Autism Quotient was established through its ability to detect differences between high functioning autistic and non-autistic individuals, as well as its ability to detect gender differences (i.e., males scored higher than females). Finally, non-significant differences between the general population and university groups indicated that the Autism Quotient is not sensitive to IQ or socio-economic status, thus allowing for a university population to be studied free from confounding variables.

Bergen Dichotic Listening Test (Hugdahl, 2009). The Bergen Dichotic Listening test is a test of language lateralization. Participants were required to report which syllable they head in each of the 108 pairs of simultaneously presented, $70 \mathrm{~dB}$ consonant-vowel combinations. Syllables were combinations of six stop consonants (e.g., /b/, /d/, /g/, /p/, /k/,/t/) and a vowel (/a/), which created 36 possible consonant-vowel pairs. All pairs were presented over three separate blocks, setting the total number of trials at 108, including 18 homonyms (same syllable pairs). The 18 homonyms were not be included in the analysis but were used to check for auditory or perceptual deficits. The three blocks each tested a different attention condition. In the no-forced attention condition, there was no special instruction to the participants to direct their attention. In the forced attention conditions, participants were asked to report the stimulus from the right ear or the left ear. These blocks were counterbalanced. Three scores were obtained: 
1) correct responses for each ear, 2) average correct responses across the three attention conditions for each ear, and 3) the laterality index (LI). Correct identification of stimuli from the right and left ears from each block were totalled and subsequently divided by the number of blocks which produced an average correct score for each ear with attentional bias being controlled. The average correct scores were used to calculate the laterality index (Average Right - Average Left/Average Right + Average Left) which is a measure of language lateralization. Positive laterality index scores indicated left hemisphere language dominance and negative scores indicated right hemisphere language dominance. A Bergen Dichotic Listening Test Score Sheet is provided in Appendix B.

The Bergen Dichotic Listening test has good test-retest reliability for each of the three attention conditions as noted by significant correlations between scores on multiple administrations: $r=.608$ for the non-forced, $r=.613$ for the forced right, and $r=.859$ for the forced left conditions (Hugdahl \& Hammar, 1997). The validity of the dichotic listening test has been established through a comparison with the intracarotid sodiumamobarbital injections test (Wada test), which found that two tests were $92 \%$ in concordance with each other (Hugdahl et al., 1997).

CV syllable pairs were delivered via headphones connected to a computer playing the dichotic listening stimuli. Each pair were presented at $70 \mathrm{~dB}$ and lasted for the duration of 350-400 ms followed by a 4 second interval to the next pair. Before beginning, the experimenter clearly explained the procedure of reporting the syllable heard by using the Hugdahl (2009) paragraph designed specifically for this measure. It can be found in Appendix C. The non-forced condition was always performed first and required no additional instructions for directed listening from the experimenter. The 
forced right and left conditions required the experimenter to instruct the participant to attend to one ear by pointing to the equivalent ear to focus the participant's attention before the preceding trial. These conditions were counterbalanced.

Waterloo Handedness Questionnaire (Steenhuis et al., 1990). The Waterloo Handedness Questionnaire assesses handedness. The full questionnaire is provided in Appendix D. Participants responded to 31 items using a 5-point non-forced Likert scale (e.g., the hand used to hold a needle when sewing or the hand used to pick up a penny"always the left hand," "usually the left hand," "both hands equally," "usually the right hand," "always the right hand"). Response options assessed both strength and direction of hand preference. Strength of hand preference indicated how often participants use a particular hand, and were reported through "always," "usually," and "both" responses. Strength responses allowed for finer distinctions among participants of similar hand direction. Direction of hand preference indicated which hand participants would prefer to use on any given task, and were reported through "left," "right," and "equal" responses. These responses allowed for distinctions among right, left, and ambiguously handed participants. Together, each item response indicated the preferred hand of the participant and the strength of that preference. A preliminary factor analysis revealed that items loaded onto three factors (Steenhuis et al., 1990). Two major factors (unskilled and skilled activities), and a third minor factor that only included bats and axes. The number of questions allocated to each factor was as follows: 19 items for unskilled activities, 10 items for skilled activities, and two items related to bats and axes. All items were designed to assess both distal (finger) and proximal (shoulder) movements. Scoring for individual items ranged from negative 2 and 1 for the left hand, 0 for both hands, and 
positive 1 and 2 for right hand responses. Total scores ranged from -62 (strongly left handed) to +62 (strongly right handed).

Test-retest reliability scores for each item are all significant and range from $r=$ .92 to .38 , although items pertaining to skilled activities were found overall to be more reliable than unskilled activity items (Steenhuis et al., 1990). Subject test-retest reliability is significant $(r=.69)$. Significant average concordance rates for both direction $(81 \%)$ and degree $(69 \%)$ of hand preference indicate that both are sufficiently reliable. Significant reliability for both characteristics of handedness indicates that the 5-point Likert scale reveals finer distinctions than a 3-point Likert scale. Overall test-retest reliability was $r=.88$. The measure has also been shown to have concurrent validity with the Edinburgh Handedness Inventory (Oldfield, 1971) and the Annett Hand Preference Questionnaire (Annett, 1970).

Rhythmic Tapping task (Pitre, 2006). The Rhythmic Tapping task was used as a measure of interhemispheric communication. Participants were required to keep accurate finger tapping at a speed of 120 beats per minute $(500 \mathrm{~ms}=2 \mathrm{~Hz})$ during 5 tapping trials. The 5 tapping trials were presented in this order: 1) left hand alone, 2) right hand alone, 3) 1:1 alternating between hands, 4) 3:1 left hand to right hand ratio, and 5) 3:1 right hand to left hand ratio. Left and right hand alone trials and the two 3:1 ratio trials were counterbalanced across participants. The left and right control keys were used for responding, and repeated key taps were disabled to avoid the recording of the same answer when a key was accidentally held down. Audio cues established the beat that participants were asked to tap for a 15 second training period. Then, participants were required to continue to tap to the desired beat for a further 30 seconds (i.e., the trial time). 
Only the trial time was analysed. The tapping software used a Java Native Interface external timer to record taps to within an accuracy of 0.002 milliseconds. The recorded measures were the total number of taps, the mean interval between taps (average InterResponse-Interval (IRI), and the tapping variability.

Rhythmic Tapping has good test-retest reliability $(r=.99)$ at $120(500 \mathrm{~ms}=2$ $\mathrm{Hz}), 133(450 \mathrm{~ms}=2.22 \mathrm{~Hz})$, and $150(400 \mathrm{~ms}=2.5 \mathrm{~Hz})$ beats per minute (Zelaznik, Spencer, \& Doffin, 2000). Validation of the test has been established through independent replications (Wolff et al., 1984; Wolff et al., 1990).

Before each trial, the experimenter explained the tapping task to be performed, demonstrated the task, and asked the participant to demonstrate each task to ensure they fully understood the requirements. Participants were asked to place their hands on the right and left control key in order to record the corresponding right and left index finger tapping. Once the participant started the trial, a window was displayed indicating the trial number and the instructions to follow (as shown in Appendix E). Instructions indicated the amount of time that the audio cue would last and instructed participants to continue tapping to the beat until the trial was completed. Pressing either control key caused the instructions window to disappear and activated an audio cue (i.e., a beeping sound) at the desired rate. The start of each trial was initiated by an audio metronome beat, which remained present for the first 15 seconds of each trial in order for participants to synchronize their tapping. Following this synchronization training phase, the participants were asked to continue tapping at the same beat after the audio cue terminated, until the trial has completed, which lasted for 30 seconds. This latter portion was the trial phase. A dialog box was displayed once the trial had been completed. After completion of each 
trial, participants were required to continue to the next trial. The researcher repeated the procedures starting with the demonstration of the tapping for each trial.

Additional Information Questionnaire. Participants were screened for learning disabilities (i.e., autism, dyslexia, Asperger's syndrome, ADHD), and brain injuries or anomalies (e.g., multiple concussions, fragile X syndrome). An example of the additional information questionnaire is provided in Appendix F.

\section{General procedure}

The experimenter first obtained informed and voluntary content from each participant. Participants were tested individually in a small and quiet experimental room for one hour. They completed the five following tests in order: the Autism Quotient Questionnaire, the Dichotic Listening Test, the Waterloo Handedness Questionnaire, the Bimanual Tapping Test, and the Additional Information Questionnaire. Following the testing session, participants were fully debriefed. Furthermore, contact information for Carleton Health and Counselling Services were provided in the case that the subject matter of the research created health concerns for the individual.

\section{Results}

Before performing any analyses, all measures were screened for univariate outliers defined as scores that were 3.29 SDs above or below the sample mean (See Field, 2009). A total of six univariate outliers were found (1 for AQ total and WHQ total; 2 for LH 3:1 ratio SD and RH 3:1 ratio SD). Outliers were adjusted to 3.29 SDs above or below the mean of the sample with the outlier removed. 


\section{Demographics}

Demographic information for the three broad academic discipline groups is presented in Table 2. Participants from the three categories were similar in age and the sample GPA was 9.27. As can been seen in Table, most had GPAs that ranged from B to A- (i.e., they were between 9 and 10 out of 12). To check whether there were gender differences between broad academic discipline groups, a Pearson chi-square analysis was performed. The chi-square was significant, $X^{2}(2, N=130)=7.32, p=.03$. In comparison to females, the males represented $50 \%$ of the physical science group, $25 \%$ of the biological science group, and $41 \%$ of the social science and humanities group.

Table 2

Demographic information for Physical Science $(n=44)$, Biological Science $(n=64)$, and Social Science \& Humanities $(n=22)$

\begin{tabular}{|c|c|c|c|c|c|c|}
\hline & \multirow[b]{2}{*}{$\underline{\text { Gender }}$} & \multirow[b]{2}{*}{$\underline{N}$} & \multicolumn{2}{|c|}{ Age } & \multicolumn{2}{|c|}{ GPA } \\
\hline & & & $\underline{M}$ & $\underline{S D}$ & $\underline{M}$ & $\underline{S D}$ \\
\hline \multirow{2}{*}{$\begin{array}{l}\text { Physical } \\
\text { Science }\end{array}$} & Male & 22 & 21.77 & 7.02 & 9.25 & 1.85 \\
\hline & Female & 22 & 19.82 & 1.92 & 9.57 & 1.56 \\
\hline \multirow{2}{*}{$\begin{array}{l}\text { Biological } \\
\text { Science }\end{array}$} & Male & 16 & 22.81 & 6.40 & 8.86 & 1.80 \\
\hline & Female & 48 & 22.87 & 7.04 & 9.62 & 1.77 \\
\hline \multirow{2}{*}{$\begin{array}{l}\text { Social } \\
\text { Science \& } \\
\text { Humanities }\end{array}$} & Male & 9 & 20.11 & 2.62 & 8.50 & 2.50 \\
\hline & Female & 13 & 21.08 & 4.91 & 9.82 & 2.09 \\
\hline
\end{tabular}

Note. Maximum GPAs are equal to 12. 


\section{Measures of Autistic Traits, Dichotic Listening, Waterloo Handedness \\ Questionnaire, Rhythmic Tapping}

Descriptive statistics for the Autism Spectrum Quotient Questionnaire, Dichotic Listening test, Waterloo Handedness Questionnaire, and Rhythmic Tapping test are presented in Table 3. The dichotic listening scores for two participants were dropped due to procedural issues (i.e., one participant accidentally reversed her headphones and another participant's responses were not correctly reported). In addition, the AQ social skills and communication scores for one participant were missing due to incorrect recording of answers (i.e., he accidently answered one question on the response scale for the previous question).

The descriptive statistics for each measure were consistent with those found in the literature. For the current sample, the mean AQ score $(M=18.91, S D=6.43)$ was comparable the results of other empirical research normed with large samples (see BaronCohen et al., 2001; Hurst et al., 2007). This was also true for each of the five AQ subscales. The mean and standard deviation of the dichotic listening laterality scores $(M$ $=11.52, S D=14.32)$ of the current sample were consistent with the normed results from the over 1500 participants reported in Hugdahl (2009). The distribution of scores was also consistent with established reports with extreme right handed scores $(\mathrm{Max}=49.33)$ being larger (i.e., further from zero) than extreme left handed scores (Min $=-21.95$; Hirnstein, Westerhausen, Korsnes, \& Hugdahl, 2013; Hugdahl, 2009). The WHQ (M $=31.82, S D=23.64)$ scores from the current study were consistent with empirical research conducted in both university and adult populations (Bulman-Fleming \& Bryden, 1994; Eaton, Rothman, McKeen, \& Campbell, 1998). Moreover, the Cronbach's 
coefficient alpha $(\alpha=.96)$ was high and was consistent with Steenhuis et al. (1990). Tapping variability descriptive statistics (left hand $M=.057, S D=.039$; right hand $M=$ $.046, S D=.032)$ reported in the present research were consistent with the established literature in this field (Wolff, Cohen, \& Drake, 1984, Wolff et al., 1990). As would be expected because of a higher number of right handed participants, tapping variability was lower when using the right hand compared to using the left hand. The difficulty of the task also ranged from high to low as seen by the scores which are further from or closer to zero. Therefore, it can be concluded that the reliability of each measure has been established. 
Table 3

Descriptive Statistics for the AQ, Dichotic Listening test, WHQ, and Rhythmic Tapping test

\begin{tabular}{|c|c|c|c|c|c|c|c|c|c|}
\hline & \multirow[t]{2}{*}{$\underline{N}$} & \multirow{2}{*}{$\underline{\text { Min }}$} & \multirow[t]{2}{*}{$\underline{\operatorname{Max}}$} & \multirow[t]{2}{*}{$\underline{M}$} & \multirow[t]{2}{*}{$\underline{S D}$} & \multicolumn{2}{|c|}{$\underline{\text { Skewness }}$} & \multicolumn{2}{|c|}{$\underline{\text { Kurtosis }}$} \\
\hline & & & & & & & $\underline{S E}$ & & $\underline{S E}$ \\
\hline AQ Score & 130 & 7 & 39 & 18.91 & 6.43 & $.474^{*}$ & .212 & .176 & .422 \\
\hline AQ-Social Skills & 129 & 0 & 10 & 3.02 & 2.15 & $.752 * * *$ & .213 & .058 & .423 \\
\hline AQ-Attention & 130 & 0 & 10 & 4.95 & 2.18 & .388 & .212 & -.633 & .422 \\
\hline Switching & & & & & & & & & \\
\hline AQ-Attention to Detail & 130 & 1 & 10 & 5.71 & 2.33 & -.014 & .212 & $-.840^{*}$ & .422 \\
\hline AQ-Communication & 129 & 0 & 10 & 2.57 & 2.02 & $.811 * * *$ & .213 & .652 & .423 \\
\hline AQ-Imagination & 130 & 0 & 8 & 2.67 & 1.76 & $.601 * *$ & .212 & .209 & .422 \\
\hline DL-Laterality Index & 128 & -21.95 & 49.33 & 11.52 & 14.32 & .348 & .214 & -.185 & .425 \\
\hline $\begin{array}{l}\text { Absolute DL-Laterality } \\
\text { Index }\end{array}$ & 128 & 0 & 49.33 & 14.39 & 11.42 & $.979 * * *$ & .214 & .369 & .425 \\
\hline WHQ Total & 130 & -45 & 62 & 31.82 & 23.64 & $-1.713 * * *$ & .212 & $2.745 * * *$ & .422 \\
\hline Absolute WHQ Total & 130 & 1 & 62 & 37.65 & 12.46 & -.214 & .212 & -.286 & .422 \\
\hline $\begin{array}{l}\text { LH 3:1 Tapping } \\
\text { Variability }\end{array}$ & 130 & .0146 & .1754 & .0571 & .0392 & $1.140 * * *$ & .212 & .417 & .422 \\
\hline $\begin{array}{l}\text { RH 3:1 Tapping } \\
\text { Variability }\end{array}$ & 130 & .0162 & .1422 & .0459 & .0319 & $1.669 * * *$ & .212 & $1.767 * * *$ & .422 \\
\hline GPA & 130 & 5.0 & 12.0 & 9.40 & 1.84 & $-4.59 *$ & .212 & -.643 & .422 \\
\hline Age & 130 & 17 & 50 & 21.79 & 5.97 & $2.563 * * *$ & .212 & $7.411 * * *$ & .422 \\
\hline
\end{tabular}

Notes: $\mathrm{AQ}=$ Autism Spectrum Quotient; DL = Dichotic Listening; WHQ = Waterloo Handedness Questionnaire; LH = Left hand; RH

$=$ Right Hand.

$* p<.05 ; * * p<.01 ; * * * p<.00$ 


\section{Correlations among Variables}

To investigate the relationship between autistic-like traits and brain morphology, correlations among autistic-like traits, brain lateralization, and interhemispheric communication measures were computed. The results are shown in Table 4.

The AQ and all subscales, with the exception of the attention to details subscale, were highly correlated ranging from $r(129)=.77, p<.001$ to $r(129)=.22, p=.01$. The attention to details subscale correlated with AQ total, $r(130)=.38, p<.001$. Correlations with the other subscales which ranged from $r(129)=.11, p=.12$ to $r(129)=.02, p=.40$ were not significant, however. In addition, there was a small but significant correlation between brain lateralization measures. Dichotic listening laterality index correlated with the WHQ $r(128)=.16, p=.03$, and the Absolute Laterality Index was correlated with the Absolute WHQ $r(128)=.16, p=.04$. Finally, the two measures of interhemispheric communication were also clearly related. The Left Hand 3:1 tapping variability was correlated with the Right Hand 3:1 tapping variability $r(130)=.49, p<.001$. Unfortunately, and contrary to the hypothesis, only one significant correlation was found between measures of autistic-like traits and measures of brain lateralization and interhemispheric communication. The AQ imagination scale was significantly correlated with the Left Hand 3:1 tapping variability. No other correlations were significant. 
Table 4

Correlations among autistic-like traits, brain lateralization, and interhemispheric communication, and GPA

\begin{tabular}{|c|c|c|c|c|c|c|c|c|c|c|c|c|}
\hline & 1 & 2 & 3 & 4 & 5 & 6 & 7 & 8 & 9 & 10 & 11 & 12 \\
\hline \multicolumn{13}{|l|}{ Autistic Traits Measures } \\
\hline 1. AQ Total & - & & & & & & & & & & & \\
\hline 2. AQ Social & $.77 * * *$ & - & & & & & & & & & & \\
\hline $\begin{array}{l}\text { 3. AQ Attention } \\
\text { Switching }\end{array}$ & $.66 * * *$ & $.44 * * *$ & - & & & & & & & & & \\
\hline $\begin{array}{l}\text { 4. AQ Attention to } \\
\text { Detail }\end{array}$ & $.38 * * *$ & .11 & -.10 & - & & & & & & & & \\
\hline 5. AQ Communication & $.77 * * *$ & $.63 * * *$ & $.47 * * *$ & .02 & - & & & & & & & \\
\hline 6. AQ Imagination & $.56 * * *$ & $.22 * *$ & $.28 * * *$ & .05 & $.36 * * *$ & - & & & & & & \\
\hline $\begin{array}{l}\text { 7. Austin revised AQ } \\
\text { Total }\end{array}$ & $.93 * * *$ & $.77 * * *$ & $.58 * * *$ & $.37 * * *$ & $.75 * * *$ & $.42 * * *$ & - & & & & & \\
\hline $\begin{array}{l}\text { 8. Austin revised AQ } \\
\text { Social }\end{array}$ & $.79 * * *$ & $.82 * * *$ & $.50 * * *$ & .09 & $.72 * * *$ & $.36 * * *$ & $.89 * * *$ & - & & & & \\
\hline $\begin{array}{l}\text { 9. Austin revised AQ } \\
\text { Details }\end{array}$ & $.50 * * *$ & $.21 * *$ & $.19 *$ & $.79 * * *$ & $.15^{*}$ & $.15^{*}$ & $.59 * * *$ & $.25 * *$ & - & & & \\
\hline $\begin{array}{l}\text { 10. Austin revised AQ } \\
\text { Communication }\end{array}$ & $.62 * * *$ & $.41 * * *$ & $.53 * * *$ & -.04 & $.70 * * *$ & $.38 * * *$ & $.54 * * *$ & $.34 * * *$ & .04 & - & & \\
\hline \multicolumn{13}{|l|}{ Lateralization Measures } \\
\hline $\begin{array}{l}\text { 11. Dichotic Listening } \\
\text { Laterality Index }\end{array}$ & .06 & .08 & .03 & .12 & -.04 & -.02 & .08 & .07 & .11 & -.07 & - & \\
\hline $\begin{array}{l}\text { 12. Absolute Dichotic } \\
\text { Listening Laterality } \\
\text { Index }\end{array}$ & .10 & .09 & .03 & .13 & .11 & -.05 & .14 & .11 & .10 & .05 & $.86 * * *$ & - \\
\hline
\end{tabular}

Note. ${ }^{*} p<.05 ; * * p<.01 ; * * * p<.00$ (1-tailed test) 
Table 4 Continued.

\begin{tabular}{|c|c|c|c|c|c|c|c|c|c|c|c|c|}
\hline & 1 & 2 & 3 & 4 & 5 & 6 & 7 & 8 & 9 & 10 & 11 & 12 \\
\hline \multicolumn{13}{|l|}{ Lateralization Measures } \\
\hline 13. WHQ Total & -.10 & -.04 & -.07 & -.05 & -.12 & .00 & -.08 & .01 & -.05 & $-.22 * *$ & $.16^{*}$ & .04 \\
\hline 14. Absolute WHQ Total & -.07 & .00 & -.04 & -.09 & -.03 & -.02 & -.06 & -.03 & -.08 & -.04 & $.17^{*}$ & $.16^{*}$ \\
\hline \multicolumn{13}{|l|}{ Interhemisheric } \\
\hline \multicolumn{13}{|l|}{ Communication Measures } \\
\hline $\begin{array}{l}\text { 15. LH 3:1 tapping } \\
\text { variability }\end{array}$ & .03 & -.05 & -.04 & .05 & -.01 & $.18^{*}$ & .03 & -.01 & .05 & .05 & .05 & .03 \\
\hline $\begin{array}{l}\text { 16. } \mathrm{RH} 3: 1 \text { tapping } \\
\text { variability }\end{array}$ & .06 & -.08 & .05 & -.01 & .08 & .14 & .02 & .01 & -.02 & .09 & -.12 & -.09 \\
\hline \multicolumn{13}{|l|}{ Discriminant Measure } \\
\hline 17. Grade Point Average & .07 & .11 & .06 & .01 & .07 & -.07 & .08 & $.16^{*}$ & -.04 & -.04 & .05 & .04 \\
\hline
\end{tabular}

\begin{tabular}{|c|c|c|c|c|c|}
\hline & 13 & 14 & 15 & 16 & 17 \\
\hline $\begin{array}{c}\text { Lateralization Measures } \\
\text { 13. WHQ Total }\end{array}$ & - & & & & \\
\hline 14. Absolute WHQ Total & $.59 * * *$ & - & & & \\
\hline $\begin{array}{l}\text { Interhemisheric } \\
\text { Communication Measures }\end{array}$ & & & & & \\
\hline $\begin{array}{l}\text { 15. LH 3:1 tapping } \\
\text { variability }\end{array}$ & .07 & .00 & - & & \\
\hline $\begin{array}{l}\text { 16. RH 3:1 tapping } \\
\text { variability }\end{array}$ & -.03 & -.01 & $.49 * * *$ & - & . \\
\hline $\begin{array}{l}\text { Discriminant Measure } \\
\text { 17. Grade Point Average }\end{array}$ & .09 & .08 & -.12 & -.10 & - \\
\hline
\end{tabular}


Nevertheless, alternative versions of the AQ have been proposed and the factor structure of Baron-Cohen et al.'s (2001) questionnaire has been debated. Therefore, an examination of the AQ factor structure was carried out on the present sample. The goal was to ultimately determine if these alternate AQ factors would be correlated with measures of brain lateralization and interhemispheric communication.

Distribution of $A Q$ scores and internal consistency of a five-factor $A Q$. First, the descriptive statistic and Cronbach's coefficient alphas for the present sample were computed based on Baron-Cohen et al. (2001) five-factor structure. The results are provided in Table 5. Cronbach's coefficient alpha estimates indicate that the internal consistency of the AQ subscales ranged from marginal (social skills and attention to detail $\alpha=.65$ ) to low (imagination $\alpha=.44$ ). The internal consistency of the total AQ score was slightly below acceptable $(\alpha=.78)$.

Table 5

Autism Quotient descriptive statistics and alphas

\begin{tabular}{|c|c|c|c|c|c|}
\hline \multirow[t]{2}{*}{ Scale } & \multicolumn{5}{|l|}{$\begin{array}{l}\text { Total } \\
\text { Sample }\end{array}$} \\
\hline & $M$ & $S D$ & $\alpha$ & Skewness & Kurtosis \\
\hline AQ total & 18.91 & 6.43 & .78 & $.474 *$ & .176 \\
\hline Social Skills & 3.02 & 2.15 & .65 & $.752 * * *$ & .058 \\
\hline Attention & 4.95 & 2.18 & .60 & .388 & -.633 \\
\hline $\begin{array}{l}\text { Switching } \\
\text { Attention to } \\
\text { Detail }\end{array}$ & 5.71 & 2.33 & .65 & -.014 & $-.840^{*}$ \\
\hline Communication & 2.57 & 2.02 & .60 & $.811 * * *$ & .652 \\
\hline Imagination & 2.67 & 1.76 & .44 & $.601 * *$ & .209 \\
\hline
\end{tabular}

Note. ${ }^{*} p<.05 ; * * p<.01 ; * * * p<.00$ 
Factor structure of the AQ based on Baron-Cohen et al. (2001). Second, a principle components factor analysis with a promax rotation was performed on all 50items of the AQ with the number of factors fixed at five. This analysis was conducted to assess the applicability of Baron-Cohen et al.'s (2001) five-factor solution for the current sample. The factor loadings are shown in Appendix G. The first five factors accounted for $32.7 \%$ of the variance and eigenvalues ranged from 6.14 to 2.07 . Item loadings were not consistent with the original five-factors reported, however. Rather, the results of this factor analysis suggested that two or three major factors were underlying participants' performance on the AQ in the present sample.

An examination of the factor loadings of the original five-factors (Appendix G) revealed that $77 \%$ (10 of 13 ) and $71 \%$ (5 of 7 ) of the items loading on the first two factors respectively, corresponded to the items representing the first two factors of Austin's (2005) revised three-factor AQ. Moreover, half the items corresponding to Austin's third factor had loadings greater than .300 in the original five-factor model. The three factors suggested by Austin (i.e., Social Skills, Detail/patterns, Communication) are also more consistent with the three core features of autism than the five factors suggested by Baron-Cohen et al. (2001). Therefore, an additional factor analysis was undertaken using the present sample to test this alternative version. 


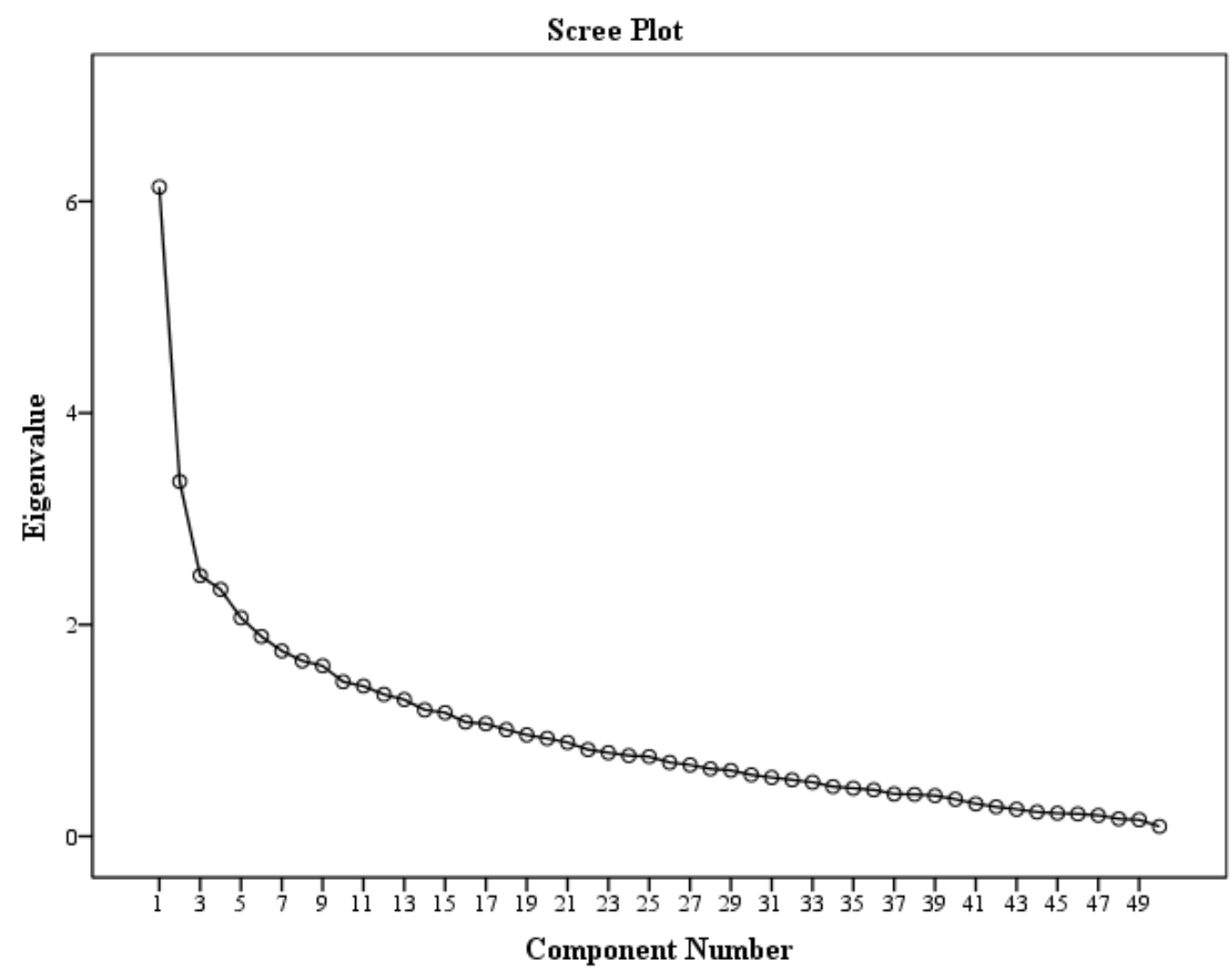

Figure 1. Scree plot for the Baron-Cohen 50-item Autism Quotient Questionnaire Distribution of scores and internal consistency of a three-factor AQ. Austin (2005) used 26-items of the original 50-items used by Baron-Cohen et al. (2001) with 12 items representing social skills, 8 items representing details and patterns, and 6 items representing communication and mindreading. The descriptive statistics and Cronbach's coefficient alphas for the present sample based on Austin's revised three-factor structure are provided in Table 6. Cronbach's coefficient alpha estimates indicate that the internal consistency of the revised AQ subscales ranged from acceptable ( (communication $\alpha=.35$ ). The internal consistency of the total revised AQ score was slightly below acceptable $(\alpha=.76)$. 
Table 6

Three-factor Autism Quotient descriptive statistics and alphas

\begin{tabular}{lccccc}
\hline Scale & \multicolumn{2}{l}{$\begin{array}{l}\text { Total } \\
\text { Sample }\end{array}$} & \multicolumn{5}{l}{ SD } & $\alpha$ & Skewness & Kurtosis \\
\cline { 2 - 6 } & 9.56 & 4.44 & .76 & $.510^{*}$ & .061 \\
\hline $\begin{array}{l}\text { Three Factor } \\
\text { AQ total }\end{array}$ & 3.31 & 3.04 & .82 & $.860 * * *$ & -.322 \\
Social & 4.54 & 1.78 & .50 & -.165 & -.423 \\
Detail & 1.70 & 1.30 & .35 & $.538 *$ & -.295 \\
Communication & & & & & \\
\hline Note. $* p<.05 ; * *<.01 ; * * p<.00$ & & &
\end{tabular}

Factor structure of the revised AQ based on Austin (2005). A principle components factor analysis with a promax rotation was performed on all 26 -items of the revised AQ with the number of factors fixed at three. This was used to assess the applicability of Austin's revised three-factor solution for the current sample. The factor loadings are shown in Appendix H. The first three factors accounted for $34.3 \%$ of the variance within the current sample, and eigenvalues that ranged from 4.82 to 1.67 . Items for the social skills and details/pattern subscales were consistent with the initial proposed three-factor structure. However, the third factor (communication/mindreading) was not consistent with the proposed structure. Additionally, the scree plot (Figure 3) again supported a two- or three-factor solution. 


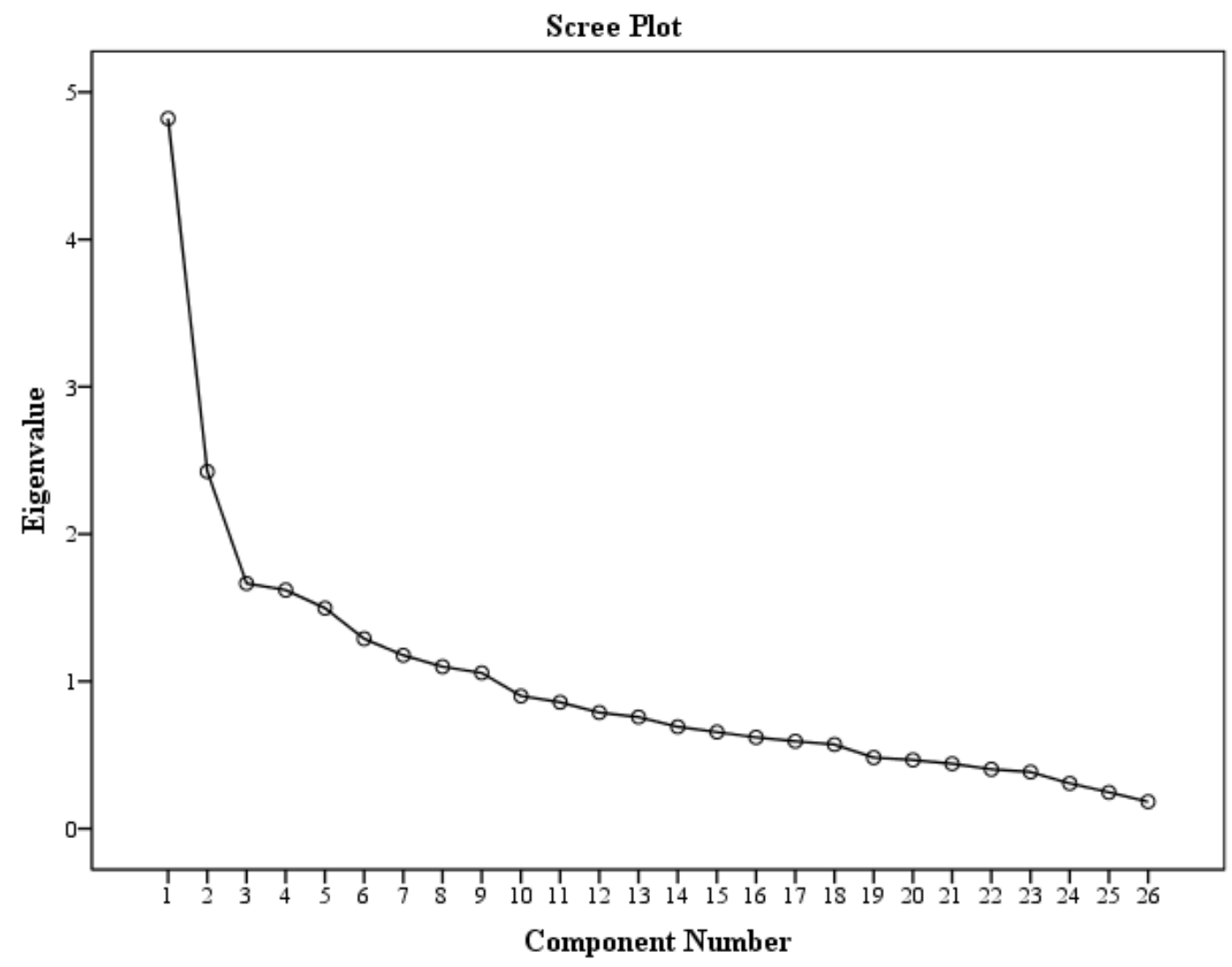

Figure 2. Scree plot for the Austin 26-item Autism Quotient Questionnaire

Both factor analyses performed on the current sample suggested a possible two or three factor structure AQ design. Moreover, Austin's (2005) three-factor revised AQ appeared to fit the current sample better than Baron-Cohen et al.'s (2001) five-factor AQ. Therefore, Austin's (2005) revised AQ and subscales were added to the correlation analysis in Table 4. The revised AQ and subscales significantly correlated with the original five-factor AQ and subscales as expected. However, the only new significant correlation with measures of brain laterality and interhemispheric communication occurred between the WHQ and the revised AQ communication subscale, $r(129)=-.22$, $p$ .005 . 


\section{Gender and Broad Academic Discipline Differences}

An initial $2 \times 3$ ANOVA was run to assess gender and the three broad academic discipline groups on the AQ. There was no interaction effect $F(2,124)=1.78, p=.17, \eta^{2}$ $=.03$. There was, however, a significant main effect of broad academic discipline group, $F(2,124)=3.43, p=.036, \eta^{2}=.052$. A post-hoc analyses using the Scheffe post hoc criterion for significance on the AQ indicated the physical science group $(M=20.55, S D$ $=6.38)$ had higher autistic-like traits than the social science/humanities group $(M=$ $16.18, S D=5.35), p=.03$. The data is shown in Figure 4 .

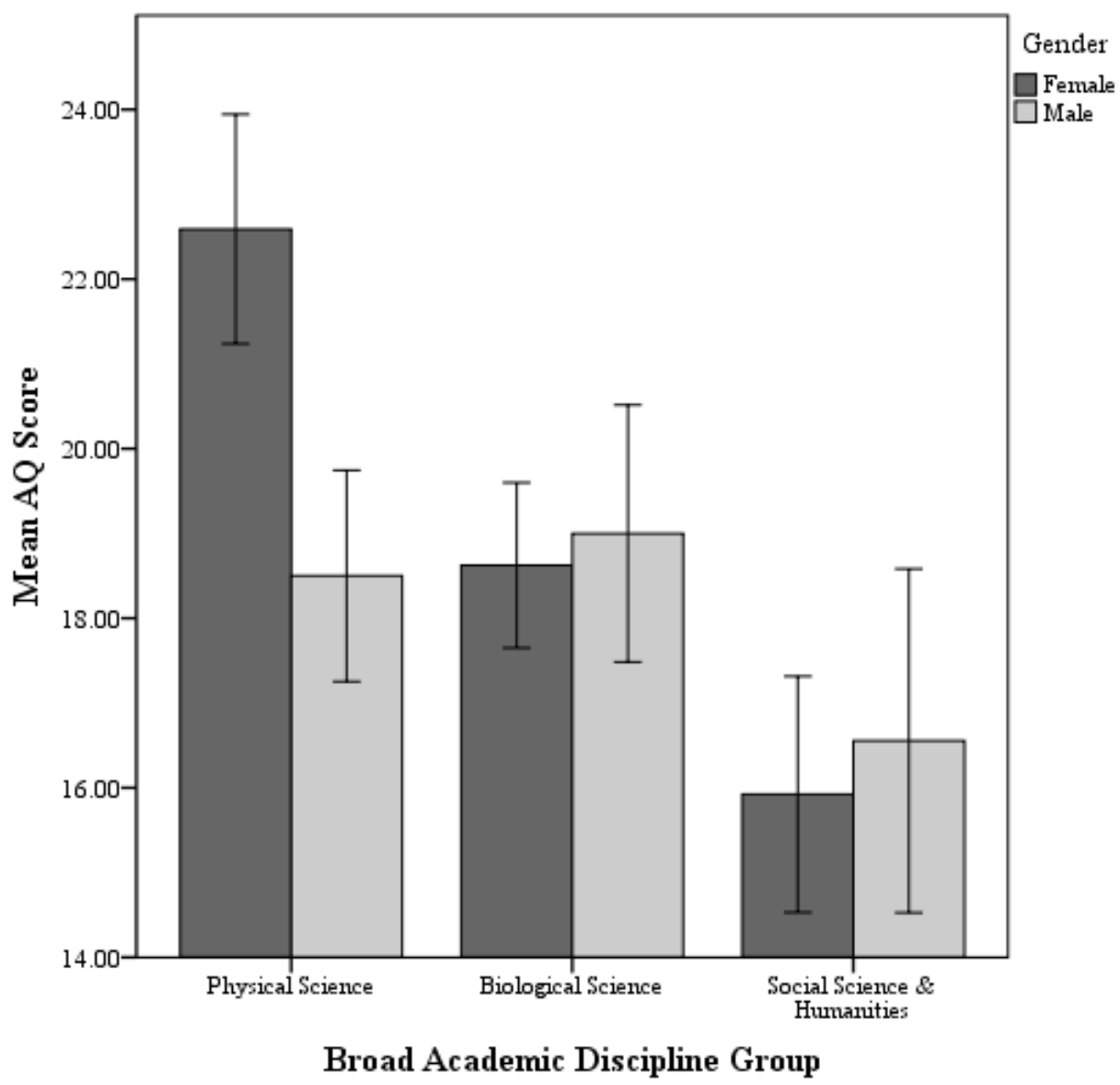

Figure 3. Mean AQ score collapsed across Academic Discipline Group with SE bars

Similar analyses were run for each of the AQ subscales, revised AQ and subscales, laterality measures, and interhemispheric communication measures. All 
interactions and most main effects were not significant. Nonetheless, a main effect of broad academic discipline group was found on the AQ social subscale, $F(2,123)=3.43$, $p=.035, \eta^{2}=.053$, the revised AQ $F(2,123)=3.79, p=.025, \eta^{2}=.058$, and on the revised AQ social subscale $F(2,124)=4.00, p=.021, \eta^{2}=.061$. Scheffe post hoc analyses on each of the significant main effects found that the physical science group ( $M$ $=10.63, S D=4.35)$ had higher in autistic-like traits than the social science/humanities group $(M=7.41, S D=3.95), p=.02$. Moreover, the physical science group also had higher autistic-like social skills $(M=4.09, S D=3.09)$ than the social science/humanities group $(M=1.91, S D=2.51), p=.021$. Post hoc analyses on the AQ social subscale did not reveal further group difference, however.

\section{Discussion}

The current research had two main goals: 1) to assess the relationship between behavioural correlates of brain morphology and autistic-like traits, and 2) to assess gender and broad academic discipline group differences in brain laterality, interhemispheric communication, and autistic-like traits. It was expected that measures of brain laterality (i.e., the dichotic listening test and WHQ) and interhemispheric communication (i.e., rhythmic tapping) would be negatively correlated with the AQ. Additionally, it was hypothesized that there would be gender and broad academic discipline group differences on a dichotic listening test, the WHQ, a rhythmic tapping test, and the AQ. Specifically, it was expected that males would have higher AQ scores and decrease laterality and interhemispheric communication scores than females. Additionally, participants in the physical sciences were expected to have higher AQ scores and decrease laterality and interhemispheric communication scores than those in 
the biological and social sciences. Unfortunately, the results did not support these central hypotheses. The following sections will discuss the specific findings of each research question in order.

\section{Research Question 1: Are behavioural correlates of brain lateralization and interhemispheric communication associated with the AQ?}

The first goal of the current research was to assess the relationship between behavioural correlates of brain morphology and autistic-like traits in the general population. To do this, I assessed the correlations between brain lateralization and interhemispheric communication measures to autistic-like traits in an undergraduate university population. Specifically, this was done by assessing the correlations among a dichotic listening test, the WHQ, a rhythmic tapping test, and the AQ and subscales. It was expected that high AQ scores would be negatively correlated with measures of brain laterality and interhemispheric communication. Unfortunately, the results did not generally support this hypothesis. Only the correlation between left hand tapping variability and the AQ imagination subscale was significant. In addition, the psychometric properties of the AQ for the present sample were assessed and a statistically sounder factor structure was proposed based on Austin's (2005) work. The correlations among these new AQ factors, brain laterality, and interhemispheric communication did not yield any encouraging results with the exception of a significant relationship between the WHQ and the revised AQ communication subscale. The discussion below will begin with an in-depth discussion on the non-significant correlations between behavioural correlates of brain morphology and autistic-like traits. This will be followed by brief discussions on the correlation between the WHQ and the 
revised AQ communication subscale, and the correlation between the left hand tapping variability and the AQ imagination subscale. Lastly, there will be a discussion regarding the factor structure of the AQ.

Overall Correlations. The correlation analysis from the current study did not support the hypothesis that autistic-like traits are connected to reduced brain laterality and interhemispheric communication. More specifically, the present results failed to replicate Lindell et al. (2009). They had found that laterality was connected to the AQ. The literature on autism is clear in its assertion that autistic individuals show reduced brain lateralization and interhemispheric communication. However, from the results of the current study, this relationship did not appear to extend into a non-clinical population. A possible explanation for this finding may have to do with the inheritance of autistic-like traits. For instance, Ronald, Larsson, Anckarsater, and Lichtenstein (2011) indicated that it is more likely that an individual would inherit one or two of the core impairments rather than all three. Because of the sub-clinical population in which autistic-like traits are generally found, it is logical to conclude that any inheritance would be on the low end of the spectrum (i.e., inheriting a single impairment rather than two or three). Accordingly, more substantial differences in brain laterality and interhemispheric communication which could be detected by using behavioural correlate measures might require the triad of impairments to be present.

Correlation (WHQ to revised AQ communication). A significant negative correlation between the WHQ and Austin's (2005) revised AQ communications scale was found. This correlation indicated that left handed individuals had higher levels of autistic-like communication impairments. This is consistent with the literature indicating 
increased left handedness in autism (Soper et al., 1986). However, it is surprising that this higher impairment in communication was not related to impairments in social skills or details as well. It is entirely possible given the number of correlations run in the present study that this is a spurious finding achieved by chance alone. This would explain why no other correlations were found between handedness and autistic-like impairments. Another possible explanation may come from research assessing the heritability of the core triad impairments. As mentioned earlier, Ronald et al. (2011) performed a structural equation model on the genetic inheritability of the triad of core impairments in autism. It found that it was more probable that an individual would inherit one or two of the core impairments than all three. Thus, for the current sample, it could be the case that certain individuals inherited only one of the core features (e.g., communication impairments). This would leave non-significant relationships between handedness and the other AQ subscales. This would also explain why the WHQ was not related to either the original or Austin (2005) revised AQ total score. Non-significant relationships between handedness and one or two of the AQ subscales may additionally make it difficult to detect a significant correlation with AQ total scores because of a small effect size.

\section{Correlation (Left hand tapping variability with $\mathrm{AQ}$ imagination). A}

surprising finding was that left hand tapping variability was positively correlated with the AQ imagination subscale. This result indicates that higher deficits in imagination were related to increased interhemispheric communication, which is contradictory to what was hypothesised. As with the correlation between handedness and communication impairments, this finding may be due solely to chance. Nevertheless, it is also possible that a third variable was responsible for this relationship. Assouline, Nicpon, and 
Dockery (2012) researched the academic achievement of gifted students with autism spectrum disorders, and found that fine motor skills predicted math achievement. Since the present experiment's participants with the highest AQ scores were found in the physical sciences (which require increased usage of mathematics), it may be speculated that the high AQ individuals from the present sample may have had superior fine motor skills. Unfortunately, excluding the tapping task, the participants' motor skills were not tested. Hence, it is impossible to assess the plausibility of this conjecture.

Factor Structure of the AQ. The factor structure of the AQ has been debated in the literature with different research groups arguing for a different number of factors ranging from two to five (Hoeskstra et al, 2008; Klossterman et al., 2011; Stewart \& Austin, 2009). Assessments of Baron-Cohen et al.'s (2001) five-factor structure and Austin's (2005) three-factor structure found that the present sample closely resembles Austin's revised AQ factor structure. Theoretically, Austin's three-factor measurement of autistic-like traits would be more consistent with the diagnostic criteria for the disorder. However, the notion that autistic-like traits may be inherited separately (Ronald et al., 2011) suggests the possibility that individuals might only differ on one of the subscales rather than on all three.

\section{Research Question 2: Are distinct patterns of AQ questionnaire scores evident in the university population?}

The second goal of this thesis was to examine gender and broad academic discipline group differences in behavioural correlates of brain morphology measures and autistic-like traits. It was hypothesized that females would display lower levels of autistic-like traits than males and increased levels of brain lateralization and 
interhemispheric communication. The results did not support these hypotheses. These results failed to replicate Baron-Cohen et al. (2001) and Austin (2005) as no significant gender differences were found on any measure.

Additionally, it was hypothesized that degrees requiring a higher content of mathematics would display higher levels of autistic-like traits and have decreased levels of brain lateralization and interhemispheric communication. The results partially supported this hypothesis. The results replicated Baron-Cohen et al. (2001), Austin (2005), and Hurst et al. (2007) and revealed that individuals in physical sciences had significantly higher overall levels of autistic-like traits on both versions of the AQ. Furthermore, individuals in physical sciences had greater impairment in social skills as assessed by Austin's (2005) revised AQ. However, no broad academic discipline group differences were found on any of the measures of brain morphology. The discussion below will begin with a discussion about the gender differences in brain morphology and autistic-like traits, followed by a discussion about broad academic discipline group differences in brain morphology and autistic-like traits.

Gender differences in brain morphology and autistic-like traits. The current study failed to find any significant gender differences on any of the behavioural correlate measures of brain lateralization or interhemispheric communication. Other research in the literature has failed to obtain gender differences in brain morphology. Voyer (2011), for example, found no gender differences in language laterality using a dichotic listening test. Similarly, Eaton et al. (1998) was unable to find gender differences on the Waterloo Handedness questionnaire using a group of 79 undergraduates. Finally, Billis and Wilber (2001) indicated that visuomotor interhemispheric communication did not appear to be 
affected by gender using a sample of 120 individuals. While the sample in the current study is fairly large $(N=130)$, it still may have been insufficient to detect the small effect sizes in one or more of the behavioural correlate measures (effect sizes ranged from $r=$ .05; WHQ to $r=.15$; Dichotic Listening). Moreover, although all the tests used in the current study were established measures, they may not have been sensitive enough to detect sub-clinical differences of brain lateralization or interhemispheric communication within the general population. In line with the previous statement, the demographic information for the behavioural correlate measures in the current study were consistent with the "normal" group demographics of other studies (e.g., Hugdahl, 2009; Eaton et al.; Wolff, Cohen, and Drake, 1984; Wolff et al., 1990). Hirnstein, Westerhausen, Korsnes, and Hugdahl's (2013) research into gender differences in brain laterality suggested the possibility that behavioural correlate measures were not sensitive enough to detect small differences in brain morphology. They detected a gender difference in language laterality using fMRI which was not detectable using the dichotic listening test. Thus, the lack of a gender effect on behavioural correlate measures puts forward at least three possibilities; 1) the present study had an insufficient sample size, 2) the behavioural correlate measures had insufficient sensitivity to detect the differences, or 3) there are no real gender differences in brain lateralization or interhemispheric communication. This last possibility is the assertion of Boles (2005) who suggests that the role of sex ranges between $.09 \%$ and $1 \%$ of the total variance in brain laterality. According to Boles, gender related differences in brain laterality in particular would contribute little to any clinical prognosis. 
The results of the current study failed to replicate Baron-Cohen et al.'s (2001) and Austin (2005) findings of significant gender differences on the AQ. However, the results are consistent with the findings of Hurst, Nelson-Gray, Mitchell and Kwapil (2006), and Hurst et al. (2007). Both of the later studies failed to find gender differences using the AQ, and Hurst et al. (2007) failed to find gender differences using Austin's revised AQ. Hurst et al. (2007) suggested the possibility of an unknown cultural confound affecting gender. This argument may have some merit because the studies by Baron-Cohen et al. (2001) and Austin (2005) were conducted in Europe, whereas the studies by Hurst et al. $(2006,2007)$ were conducted in North America. It is conceivable that differences in culture could affect the way the different genders socialize, communicate, or behave. This could cause differential responding to the items on the AQ.

\section{Broad academic discipline group differences in brain morphology and}

autistic-like traits. The current study failed to find any broad academic discipline group differences on any of the behavioural correlate measures. The same rationale used to explain lack of a gender difference can be applied to the lack of broad academic discipline group differences as well. Again, the sample size might not have been large enough, the measures might not have been sensitive enough, or there might not be any significant difference in brain lateralization or interhemispheric communication between groups.

The results of the current study did support Baron-Cohen et al. (2001) and Hurst et al. (2007) findings of broad academic discipline group differences on both the AQ and Austin's (2005) revised AQ. Specifically, individuals in the physical sciences had higher levels of autistic-like traits that those in the social sciences and humanities. According to 
Baron-Cohen et al. (2001) this is related to the amount of math content used in the physical sciences. Unlike gender differences, broad academic discipline group differences based on the amount of mathematics required has been replicated consistently in both Europe (Austin, 2005; Baron-Cohen et al., 2001; Hoekstra et al., 2008) and North America (Hurst et al., 2006; 2007). However, the significant difference between the physical science group and the biological science group, as well as the biological science group and the social science and humanities group reported by Baron-Cohen et al. (2001) was not replicated. This finding may be due to the way in which the broad academic discipline groups were created for the current study. As discussed earlier, the current broad academic discipline groups were created by collapsing the hierarchies of BaronCohen et al. (2001) and Simonton (2009). This created slightly different broad academic discipline groups (especially the biological science group) because they represented both mathematical content and scientific creativity. Moreover, the sample size in the BaronCohen et al. (2001) study was considerably larger than the sample used in the current study. A final explanation for non-significant group differences between physical science degrees and biological science degrees may be due to the lower than expected AQ scores of physical science males. Physical science males were expected to have the highest levels of autistic-like traits. The low scores for this group in the current study may have lowered the average AQ score sufficiently to create a non-significant finding. This raises an important question: What could lead to high autistic-like trait individuals not participating in this study? The answer may lie in the procedures employed in the current study which required participants to test within a lab setting. Because a lack of social skills is associated with autism, higher AQ scoring individuals may have decided that the 
cost of participating in a social situation far exceeded the benefits (i.e., the compensation). Nevertheless, it does appear that individuals who pursue physical science degrees do have higher levels of autistic-like traits and higher impairments in social skills than those pursuing social science or humanities degrees.

\section{Limitations and Future Directions}

One of the major limitations of the current research was attaining a sample that represented the full range of sub-clinical autistic-like traits. Of specific concern was finding enough individuals with high levels of autistic-like traits to participate. The very nature of the autistic disorder suggests that these individuals would have high levels of social skill impairments, which also extends to those with high levels of autistic-like traits. The requirement of an in lab testing session may have been too much of a social cost to outweigh any monetary gains for participation. Although the current sample did test a wide range of students from a variety of academic disciplines, gender differences in AQ score did suggest that I perhaps did not have a representative sample of physical science males (the expected highest autistic-like individuals). The physical science males in the current study had less autistic-like traits than either gender in the biological sciences.

An additional limitation was the use of the AQ itself. Two different versions were employed in the current study and produced somewhat similar results. However, the Austin's (2005) revised AQ produced a significant correlation, which the original BaronCohen et al.'s (2001) AQ did not. Austin's revised AQ accounted for a slightly higher proportion of the variance in autistic-like traits, and also found a significant group difference on the social skill subscale. Hurst et al. (2007) suggested that the AQ is a 
promising measure to assess autistic-like traits. They did argue, however, that it needed further psychometric testing. The results from the current study support this opinion, as both versions of the AQ had issues with internal consistency. Future research should focus on the psychometric properties of the AQ. In this endeavour, item response curves and modified structural equation models may serve as an additional tool for researchers assessing which of the 50 items best represent the underlying latent factor and reduce the amount of measurement error.

\section{Conclusion}

The results from the current study suggest that using behavioural correlate measures does not provide concrete evidence of differences in brain morphology in connection to autistic-like traits. A single finding demonstrated that left-handedness was associated with increased autistic-like communication impairment, while preserving social skills and attention for details and patterns. This may suggest that not all autisticlike traits are inherited together. This being said, interpretation of these findings should be undertaken with utmost caution. It cannot be ignored that the research failed to find any other significant relationship to support this position. Thus, the results may also support the possibility that brain morphology is not associated with autistic-like traits in the general population. As explained in the future directions section, there are many aspects of autistic research in this area to be considered. In such a homogeneous population, cautious interpretation of all findings in the field will be advised. To that end, the present study provides a platform for further investigation into the connection between brain morphology and autistic-like traits. 


\section{References}

Abrahams, B. S., \& Geschwind, D. H. (2008). Advances in autism genetics: on the threshold of a new neurobiology. Nature Reviews Genetics, 9, 341-355.

American Psychiatric Association. (2000). Diagnostic and statistical manual of mental disorders (4th ed., text rev.). Washington, DC: American Psychiatric Association.

Anderson, J. S., Druzgal, T. J., Froehlich, A., DuBray, M. B., Lange, N., Alexander, A. L., . . Lainhart, J. E. (2011). Decreased interhemispheric functional connectivity in autism. Cerebral Cortex, 21, 1134-1146.

Annett, M. (1970). A classification of hand preference by association analysis. British Jouranl of Psychology, 61, 303-321.

Annett, M. (1998). Handedness and cerebral dominance: the right shift theory. Journal of Neuropsychiatry, 10(4), 459-469.

Assouline, S. G., Nicpon, M. F., \& Dockery, L. (2012). Predicting the academic achievement of gifted students with autism spectrum disorder. Journal of Autism and Developmental Disorders, 42, 1781-1789.

Austin, E. J. (2005). Personality correlates of the broader autism phenotype as assessed by the autism spectrum quotient (AQ). Personality and Individual Differences, $38,451-460$.

Badaruddin, D. H., Andrews, G. L., Bolte, S., Schilmoeller, K. J., Paul, L. K., \& Brown, W. S. (2007). Social and behavioral problems of children with agenesis of the corpus callosum. Child Psychiatry and Human Development, 38, 287-302. 
Bailey, A., Le Couteur, A., Gottesman, I., Bolton, P., Simonoff, E., Yuzda, E., \& Rutter, M. (1995). Autism as a strongly genetic disorder: evidence from a British twin study. Psychological Medicine, 25, 63-77.

Baron-Cohen, S. (1988). Social and pragmatic deficits in autism: cognitive or affective? Journal of Autism and Developmental Disorders, 18, 515-526.

Baron-Cohen, S. (2002). The extreme male brain theory of autism. Trends in Cognitive Sciences, 6(6), 248-254.

Baron-Cohen, S., \& Hammer, J. (1997). Is autism an extreme form of the male brain? Advances in Infancy Research, 11, 193-217.

Baron-Cohen, S., Jolliffe, T., Mortimore, C., \& Robertson, M. (1997). Another advanced test of theory of mind: evidence from very high functioning adults with autism or asperger syndrome. Journal of Child Psychology and Psychiatry and Allied Disciplines, 38, 813-822.

Baron-Cohen, S., Leslie, A. M., \& Frith, U. (1985). Does the autistic-child have a theory of mind. Cognition, 21, 37-46.

Baron-Cohen, S., Lombardo, M. V., Auyeung, B., Ashwin, E., Chakrabarti, B., \& Knickmeyer, R. (2011). Why are autism spectrum conditions more prevalent in males? PLoS Biology, 9, e1001081.

Baron-Cohen, S., Wheelwright, S., Skinner, R., Martin, J., \& Clubley, E. (2001). The autism-spectrum quotient (AQ): evidece from asperger syndrome/highfunctioning autism, males and females, scientists and mathematicians. Journal of Autism and Developmental Disorders, 31(1), 5-17. 
Bellis, T. J., \& Wilber, L. A. (2001). Effects of aging and gender on interhemispheric function. Jouranl of speech, Language, and Hearing Research, 44, 246-263.

Bennetto, L., Pennington, B. F., \& Rogers, S. J. (1996). Intact and impaired memory functions in autism. Child Development, 67, 1816-1835.

Bishop, D. V., Maybery, M., Maley, A., Wong, D., Hill, W., \& Hallmayer, J. (2004). Using self-report to identify the broad phenotype in parents of children with autistic spectrum disorders: a study using the autism-spectrum ouotient. Journal of Child Psychology and Psychiatry, 45, 1431-1436.

Boles, D. B. (2005). A large-sample study of sex differences in functional cerebral lateralization. Journal of Clinical and Experimental Neuropsychology, 27, 759768.

Bolton, P., Macdonald, H., Pickles, A., Rios, P., Goode, S., Crowson, M., . . Rutter, M. (1994). A case-control familiy history study of autism. Journal of Child Psychology, 35, 877-900.

Brown, W. S., \& Paul, L. K. (2000). Cognitive and psychosocial deficits in agenesis of the corpus callosum with normal intelligence. Cognitive Neuropsychiatry, 5, 135157.

Brown, W. S., Paul, L. K., Symingtion, M., \& Dietrich, R. (2005). Comprehension of humor in primary agenesis of the corpus callosum. Neuropsychologia, 43, 906916.

Brown, W. S., Symingtion, M., VanLancker-Sidtis, D., Dietrich, R., \& Paul, L. K. (2005). Paralinguistic processing in children with callosal agenesis: emergence of neurolinguistic deficits. Brain and Language, 93, 135-139. 
Bryden, M. (1975). Speech lateralization in families: A preliminary study using dichotic listening. Brain and Language, 2, 201-211.

Bulman-Fleming, M. B., \& Bryden, M. P. (1994). Simultaneous verbal and affective laterality effects. Neuropsychologia, 32, 787-797.

Chambres, P., Bonin, D., \& Grenier, K. (2001). Indirect and subliminal 'mere exposure" effect: Implicit aspect of attitude formation. Current Psychology Letters: Behaviour, Brain and Cognition, 1, 85-100.

Chura, L. R., Lombardo, M. V., Ashwin, E., Auyeung, B., Charabarti, B., Bullmore, E. T., \& Baron-Cohen, S. (2010). Organizational effects of fetal testosterone on human corpus callosum size and asymmetry. Psychoneuroendocrinology, 35, $122-132$.

Constantino, J. N., \& Todd, R. D. (2003). Autistic traits in the general population. Archive of General Psychiatry, 60, 524-530.

Constantino, J. N., \& Todd, R. D. (2005). Intergenerational transmission of subthreshold autistic traits in the general population. Biological Psychiatry, 57, 655-660.

Corriveau, K. H., \& Goswami, U. (2009). Rhythmic motor entrainment in children with speech and language impairments: tapping to the beat. Cortex, 45, 119-130.

Cosgrove, K. P., Mazure, C. M., \& Staley, J. K. (2007). Evolving knowledge of sex differences in brain structure, function and chemistry. Biological Psychiatry, 62, 847-855.

Eaton, W. O., Rothman, D. B., McKeen, N. A., \& Campbell, D. W. (1998). Something sinistral going on? Asymmetry in arm movement frequency. Laterality, 3, 311322. 
Escalante-Mead, P. R., Minshew, N. J., \& Sweeney, J. A. (2003). Abnormal brain lateralization in high-functioning autism. Journal of Autism and Developmental Disorders, 33, 539-543.

Field, A. (2009). Discovering statistics using spss. London: SAGE Publications Ltd. Folstein, S., \& Rutter, M. (1977). Infantile autism: a genetic study of 21 twin pairs. Journal of Child Psychology, 18, 297-321.

Fournier, K. A., Hass, C. J., Naik, S. K., Lodha, N., \& Cauraugh, J. H. (2010). Motor coordination in autism spectrum disorders: a synthesis and meta-analysis. Journal of Autism and Developmental Disorders, 40, 1227-1240.

Frith, U., \& Happe, F. (1994). Autism: beyond "theory of mind". Cognition, 50, 115-132.

George, L. (2010). Book Review. Laterality, 15, 475-480.

Gerdts, J., \& Bernier, R. (2011). The broader autism phenotype and its implicaitons on the etiology and treatment of autism spectrum disorders. Autism Research and Treatment, 19, 1-19.

Gray, D. E. (1993). Perceptions of stigma: the parents of autistic children. Sociology of Health and Illness, 15, 102-120.

Happe, F. G. (1994). An advanced test of theory of mind — understanding of story characters thoughts and feelings by able autistic, mentally—handicapped, and normal_ children and adults. Journal of Autism and Developmental Disorders, 24, 129-154.

Hardyck, C., \& Petrinovich, L. F. (1977). Left-handedness. Psychological Bulletin, 84, $385-404$. 
Harnum, M., Duffy, J., \& Ferguson, D. A. (2007). Adults' versus children’s perceptions of a child with autism or attention deficit hyperactivity disorder. Journal of Autism and Developmental Disorders, 37,1337-1343.

Hartley, S. L., \& Sikora, D. M. (2009). Sex differences in autism spectrum disorder: an examination of developmental functioning, autistic symptoms, and coexisting behavior problems in toddlers. Journal of Autism and Developmental Disorders, $39,1715-1722$.

Hauck, J. A., \& Dewey, D. (2001). Hand preference and motor functioning in children with autism. Journal of Autism and Developmental Disorders, 31, 265-277.

Hirnstein, M., Westerhausen, R., Korsnes, M. S., \& Hugdahl, K. (2013). Sex differences in language asymmetry are age-dependent and small: A large-scale, consonantvowel dichotic listening study with behaivoural and fMRI data. Cortex, 49, 19101921.

Hiscock, M., Inch, R., \& Kinsbourne, M. (1999). Allocation of attention in dichotic listeing: Differential effects on the detection and localization of signals. Neuropsychologia, 13(3), 404-414.

Hoekstra, R. A., Bartels, M., Cath, D. C., \& Boomsma, D. I. (2008). Factor structure, reliability and criterion validity of the autism-spectrum quotient (AQ): a study in Dutch population and patient groups. Journal of Autism and Developmental Disorders, 38, 1555-1566.

Hugdahl, K. (2009). Dichotic Listening with CV-Syllables. Department of Biological and Medical Psychology University of Bergen, Norway. 
Hugdahl, K., \& Andersson, L. (1986). The "forced-attention paradigm" in dichotic listening to cv-syllables: a comparison between adults and children. Cortex, 22, 417-432.

Hugdahl, K., \& Hammar, A. (1997). Test-retest reliability for the consonant-vowel syllables dichotic listening paradigm. Journal of Clinical and Experimental Neuropsychology, 19(5), 667-675.

Hugdahl, K., Carlsson, G., \& Eichele, T. (2001). Age effects in dichotic listening to consonant-vowel syllables: interactions with attention. Developmental Neuropsychology, 20(1), 445-457.

Hugdahl, K., Carlsson, G., Uvebrant, P., \& Lundervold, A. J. (1997). Dichotic-listening performance and intracarotid injections of amobarbital in children and adolescents. Archives of Neurology, 54, 1494-1500.

Hugdahl, K., Westerhausen, R., Alho, K., Medvedev, S., \& Hamalainen, H. (2008). The effect of stimulus intensity on the right ear advantage in dichotic listening. Neuroscience Letters, 431, 90-94.

Hurley, R. S., Losh, M., Parlier, M., Reznick, J. S., \& Piven, J. (2007). The broad autism phenotype questionnaire. Journal of Autism and Developmental Disorders, 37 , 1679-1690.

Hurst, R. M., Mitchell, J. T., Kimbrel, N. A., Kwapil, T. K., \& Nelson-Gray, R. O. (2007). Examination of the reliability and factor structure of the autism spectrum quotient (AQ) in a non-clinical sample. Personality and Individual Differences, 43, 1938-1949. 
Hurst, R. M., Neslon-Gray, R. O., Mitchell, J. T., \& Kwapil, T. R. (2006). The relationship of Asperger's characteristics and Schizotypal Personlaity traits in a non-clinical adult sample. Journal of Autism and Developmental Disorders, 37 , 1711-1720.

Isenhower, R. W., Marsh, K. L., Richardson, M. J., Helt, M., Schmidt, R., \& Fein, D. (2012). Rhythmic bimanual coordination is impaired in young children with autism spectrum disorder. Research in Autism Spectrum Disorders, 6, 25-31.

Just, M. A., Cherkassky, V. L., Keller, T. A., \& Minshew, N. J. (2004). Cortical activation and synchronization during sentence comprehension in highfunctioning autism: evidence of underconnectivity. Brain, 127, 1811-1821.

Just, M. A., Cherkassky, V. L., Keller, T. A., Kana, R. K., \& Minshew, N. J. (2007). Functional and anatomical cortical underconnectivity in autism: evidence from an fMRI study of an executive function task and corpus callosum morphometry. Cerebral Cortex, 17, 951-961.

Karmiloff-Smith, A., Klima, E., Bellugi, U., Grant, J., \& Baron-Cohen, S. (1995). Is there a social module? language, face processing, and theory of mind in individuals with Williams syndrome. Journal of Cognitive Neuroscience, 7, 196-208.

Keary, C. J., Minshew, N. J., Bansal, R., Coradia, D., Fedorov, S., Keshavan, M. S., \& Hardan, A. Y. (2009). Copus callosum volume and neurocognition in autism. Journal of Autism and Developmental Disorders, 39, 834-841.

Ketelaars, C., Horwitz, E., Sytema, S., Bos, J., Wiersma, D., Minderaa, R., \& Hartman, C. A. (2008). Brief report: adults with mild autism spectrum disorders (ASD): 
scores on the autism spectrum quotient (AQ) and comorbid psychopathology. Journal of Autism and Developmental Disorders, 38, 176-180.

Kimura, D. (1961a). Some effects of temporal-lobe damage on auditory perception. Canadian Journal of Psychology, 15, 156-165.

Kimura, D. (1961b). Cerebral dominance and the perception of verbal stimuli. Canadian Journal of Pcyhology, 15, 166-171.

Klimkeit, E. I., \& Bradshaw, J. L. (2006). Anomalous lateralisation in neurodevelopmental disorders. Cortex, 42, 113-116.

Kloosterman, P. H., Keefer, K. V., Kelley, E. A., Summerfeldt, L. J., \& Parker, J. D. (2011). Evaluation of the factor structure of the autism-spectrum quotient. Personality and Individual Differences, 50, 310-314.

Levy, F. (2007). Theories of autism. Australian and New Zealand Journal of Psychiatry, 41, 859-868.

Lindell, A. K. (2006). In your right mind: right hemisphere contributions to language processing and production. Neuropsychological Review, 16, 131-148.

Lindell, A. K., Notice, K., \& Withers, K. (2009). Reduced language processing asymmetry in non-autistic individuals with high levels of autism traits. Laterality, $14,457-472$.

Lopez, B. R., Lincoln, A. J., Ozonoff, S., \& Lai, Z. (2005). Examining the relatinship between executive functions and restricted, repetitive symptoms of autistic disorder. Journal of Autism and Developmental Disorders, 35, 445-460. 
Marion, S. D., Kilian, S. C., Naramor, T. L., \& Brown, W. S. (2003). Normal development of bimanual coordination: visuomotor and interhemispheric contributions. Developmental Neuorpsychology, 23(3), 399-421.

Martin, I., \& McDonald, S. (2003). Weak coherence, no theory of mind, or executive dysfunction? solving the puzzle of pragmatic language disorders. Brain and Language, 85, 451-466.

McMeekan, E. R., \& Lishman, W. A. (1975). Retest reliabilities and interrelationship of the annett and preference questionnaire and the edinburgh handedness inventory. Brisith Journal of Psychology, 66(1), 53-59.

Medland, S. E., Duffy, D. L., Wright, M. J., Geffen, G. M., Hay, D. A., Levy, F., . . Boomsma, D. I. (2009). Genetic influences on handedness: Data from 25,732 Australian and Dutch twin families. Neuropsycholgia, 47, 330-337.

Medland, S. E., Wright, M. J., Geffen, G. M., Hay, D. A., Levy, F., Martin, N. G., \& Duffy, D. L. (1997). Special twin environments, genetic influences and their effects on the handedness of twins and their siblings. Twin Research, 6, 119-130.

Minshew, N. J., Goldstein, G., \& Siegel, D. J. (1995). Speech and language in highfunctioning autistic individuals. Neuropsychology, 9, 255-261.

Mostofsky, S. H., Powell, S. K., Simmonds, D. J., Goldberg, M. C., Caffo, B., \& Pekar, J. (2009). Decreased connectivity and cerebellar activity in autism during motor task performance. Brain, 132, 2413-2425.

Oldfield, R. (1971). The assessment and analysis of handedness: the edinburgh inventory. Neurophsychologia, 9, 97-113. 
Ozonoff, S., \& Jensen, J. (1999). Specific executive function profiles in three neurodevelopmental disorders. Journal of Autism and Developmental Disorders, $29,171-177$.

Ozonoff, S., Pennington, B. F., \& Rogers, S. J. (1991). Executive function deficits in high-functioning autistic individuals — relationship to theory of mind. Journal of Child Psychology and Psychiatry and Allied Diciplines, 32, 1081-1105.

Ozonoff, S., Rogers, S. J., Farnham, J. M., \& Pennington, B. F. (1993). Can standard measures identify subclinical markers of autism. Journal of autism and Developmental Disorders, 23, 429-441.

Ozonoff, S., Strayer, D. L., McMahon, W. M., \& Filloux, F. (1994). Executive function abilities in autism and Tourette syndrome: An information processing approach. Journal of Child Psychology and Psychiatry, 35, 1015-1032.

Parritz, R. H., \& Troy, M. F. (2011). Disorders of Childhood: Development and Psychopathology 1st Ed. Belmont: Wadsworth Cengage Learning. ISBN-10: 0534592740.

Pascualvaca, D. M., Fantie, B. D., Papageorgiou, M., \& Mirsky, A. F. (1998). Attentional capacities in children with autism: Is there a general deficit in shifting focus? Journal of Autism and Developmental Disorders, 28, 467-478.

Paul, L. K., Van Lancker-Sidtis, D., Schieffer, B., Dietrich, R., \& Brown, W. S. (2003). Communicative deficits in agenesis of the corpus callosum: nonliteral language and affective prosody. Brain and Language, 85, 313-324.

Peters, M. (1998). Description and validation of a flexible and broadly usable handedness questionnaire. Laterality, 3(1), 77-96. 
Pitre, S. (2006). Hand Tapping Software Version 2.0 User Guide. School of Computer Science, Carleton University.

Plaisted, K. C. (2001). Reduced generalization in autism: an alternative to weak central coherence. In J. A. Burack, T. Charman, N. Yirmiya, \& P. R. Zelazo, The development of autism: Perspective from theory and research (pp. 149-172). Mahwah, NJ: Lawrence Erlbaum Associates.

Plaisted, K., O’Riordan, M., \& Baron-Cohen, S. (1998a). Enhanced discrimination of novel, highly similar stimuli by adults with autism during a perceptual learning task. Journal of Child Psychology and Psychiatry and Allied Disciplines, , 39, $765-775$.

Plaisted, K., O'Riordan, M., \& Baron-Cohen, S. (1998b). Enhanced visual search for a conjunctive target in autism: a research note. Journal of Child Psychology and Psychiatry and Allied Disciplines, , 39, 777-783.

Plaisted, K., Swettenham, J., \& Rees, L. (1999). Children with autism show local precedence in a divided attention task and global precedence in a selective attention task. Journal of Child Psychology and Psychiatry and Allied Disciplines, 40, 733-742.

Price, K. J., Edgell, D., \& Kerns, K. A. (2012). Timing deficits are implicated in motor dysfunction in Asperger's syndrome. Research in Autism Spectrum Disorders, 6, 857-860.

Rajendran, G., \& Mitchell, P. (2007). Cognitive theories of autism. Developmental Review, 27, 224-260. 
Rimol, L. M., Eichele, T., \& Hugdahl, K. (2006). The effect of voice-onset-time on dichotic listening with consonant-vowel syllables. Neuropsychologia, 44, 191196.

Rinehart, N. J., Bradshaw, J. L., Moss, S. A., Brereton, A. V., \& Tonge, B. J. (2000). Atypical interference of local detail on global processing in high-functioning autism and asperger's disorder. Journal of Child Psychology and Psychiatry and Allied Disciplines, 41, 769-778.

Ronald, A., Larsson, H., Anckarsater, H., \& Lichtenstein, P. (2011). A twin study of autism symptoms in Sweden. Molecular Psychiatry, 16, 1039-1047.

Saetrevik, B., \& Hugdahl, K. (2007). Endogenous and exogenous control of attention in dichotic listening. Neuropsychology, 21, 285-290.

Sauerwein, H. C., \& Lassonde, M. (1994). Cognitive and sensori-motor functioning in the absence of the corpus callosum: neuropsychological studies in callosal agenesis and callosotomized patients. Behavioural Brain Research, 64, 229-240.

Schroeder, J. H., Desrocher, M., Bebko, J. M., \& Cappadocia, M. C. (2010). The neurobiology of autism: theoretical applications. Research in Autism Spectrum Disorders, 4, 555-564.

Shah, A., \& Frith, U. (1993). Why do autistic individuals show superior performance on the block design task. Journal of Child Psychology and Psychiatry and Allied Disciplines, 34, 1351-1364.

Simonton, D. K. (2009). Varieties of (scientific) creativity: A hierarchical model for doman-specific disposition, developmnet, and achievement. Perspectives on Psychological Science, 4(5), 441-452. 
Soper, H. V., Satz, P., Orsini, D. L., Henry, R. R., Zvi, J. C., \& Schulman, M. (1986). Handedness patterns in autism suggest subtypes. Journal of Autism and Developmental Disorders, 16, 155-167.

Steenhuis, R. E., \& Bryden, M. (1989). Different dimensions of hand preference that relate to skilled and unskilled activities. Cortex, 25, 289-304.

Steenhuis, R. E., Bryden, M., Schwartz, M., \& Lawson, S. (1990). Reliability of hand preference items and factors. Journal of Clinical and Experimental Neuorpsychology, 12(6), 921-930.

Stewart, M. E., \& Austin, E. J. (2009). The structure of the autism-spectrum quotient (AQ): Evidence from a student sample in Scotland. Personality and Individual Differences, 47, 224-228.

Swaim, K. F., \& Morgan, S. B. (2001). Children's attitudes and behavioral intentions toward a peer with autistic behaviors: Does a brief educational intervention have an effect? Journal of Autism and Developmental Disorders, 31, 195-205.

Tabachnick, B. G., \& Fidell, L. S. (2007). Using multivariate statistics. Boston: Pearson Education Inc.

Tager-Flusberg, H. (2004). Strategies for conducting research on language in autism. Journal of Autism and Developmental Disorders, 34, 75-80.

Vidal, C. N., Nicholson, R., DeVito, T. J., Hayashi, K. M., Geaga, J. A., Drost, D. J., . . . Thompson, P. M. (2005). Mapping corpus callosum deficits in autism: an index of aberrant cortical connectivity. Biological Psychicatry, 60, 218-225.

Voyer, D. (2011). Sex difference in dichotic listening. Brain and Cognition, 76, 245-255. 
Waterhouse, L. (2008). Autism overflows: increasing prevalence and proliferating theories. Neuropsychological Review, 18, 273-286.

Whitehouse, A. J., \& Bishop, D. V. (2008). Cerebral dominance for language function in adults with specific language impairment or autism. Brain, 131, 3193-3200.

Wittling, R., Schweiger, E., Rizhova, L., Vershinina, E., \& Starup, L. (2009). A simple method for measuring brain asymmetry in children: application to autism. Behavior Research Methods, 41, 812-819.

Wolff, P. H., Cohen, C., \& Drake, C. (1984). Impaired motor timing control in specific reading retardation. Neuropsychologia, 22, 587-600.

Wolff, P. H., Michel, G. F., Ovrut, M., \& Drake, C. (1990). Rate and timing precision of motor coordination in developmental dyslexia. Developmental Psychology, 26, 349-359.

Yeo, R. A., Gangestad, S. W., Thoma, R., Shaw, P., \& Repa, K. (1997). Developmental Instability and Cerebral Lateralization. Neuropsychology, 11, 522-561.

Zelaznik, H. N., Spencer, R. M., \& Doffin, J. G. (2000). Temporal precision in tapping and circle drawing movements at preferred rates is not correlated: Further evidence against timing as a general-purpose ability. Journal of Motor Behavior, (32), 193-199.

Zwaigenbaum, L., Thurm, A., Stone, W., Baranek, G., Bryson, S., Iverson, J., . . . Sigman, M. (2007). Studying the emergence of autism spectrum disorders in highrisk infants: methodological and practical issues. Journal of Autism and Developmental Disorders, 37, 466-480. 


\section{Appendices}

\section{Appendix A: Autism Quotient Questionnaire}

\section{The Autistic-Spectrum Quotient}

1. I prefer to do things with others rather than on my own.

2. I prefer to do things the same way over and over again.

3. If I try to imagine something, I find it very easy to create a picture in my mind.

4. I frequently get so strongly absorbed in one thing that $I$ lose sight of other things.

5. I often notice small sounds when others do not.

6. I usually notice car number plates or similar strings of information.

7. Other people frequently tell me that what I've said is impolite, even though I think it is polite.

8 . When I'm reading a story, I can easily imagine what the characters might look like.

9. I am fascinated by dates.

10. In a social group, I can easily keep track of several different people's conversations.

11. I find social situations easy.

12. I tend to notice details that others do not.

13. I would rather go to a library than a party.

14. I find making up stories easy.

15. I find myself drawn more strongly to people than to things.

16. I tend to have very strong interests, which I get upset about if I can't pursue.

17. I enjoy social chit-chat.

18. When I talk, it isn't always easy for others to get a word in edgeways.

19. I am fascinated by numbers.

20. When I'm reading a story, I find it difficult to work out the characters' intentions.

21 . I don't particularly enjoy reading fiction.

22. I find it hard to make new friends.

23. I notice patterns in things all the time

24. I would rather go to the theatre than a museum.

25 . It does not upset me if my daily routine is distubed.

26. I frequently find that I don't know how to keep a conversation going.

\begin{tabular}{|c|c|c|c|}
\hline definitely agree & slightly agree & slightly disagree & definitely disagree \\
\hline definitely agree & slightly agree & slightly disagree & definitely disagree \\
\hline definitely agree & slightly agree & slightly disagree & definitely disagree \\
\hline definitely agree & slightly agree & slightly disagree & definitely disagree \\
\hline definitely agree & slightly agree & slightly disagree & definitely disagree \\
\hline definitely agree & slightly agree & slightly disagree & definitely disagree \\
\hline definitely agree & slightly agree & slightly disagree & definitely disagree \\
\hline definitely agree & slightly agree & slightly disagree & definitely disagree \\
\hline $\begin{array}{l}\text { definitely agree } \\
\text { definitely agree }\end{array}$ & $\begin{array}{l}\text { slightly agree } \\
\text { slightly agree }\end{array}$ & $\begin{array}{l}\text { slightly disagree } \\
\text { slightly disagree }\end{array}$ & $\begin{array}{l}\text { definitely disagree } \\
\text { definitely disagree }\end{array}$ \\
\hline definitely agree & slightly agree & slightly disagree & definitely disagree \\
\hline definitely agree & slightly agree & slightly disagree & definitely disagree \\
\hline definitely agree & slightly agree & slightly disagree & definitely disagree \\
\hline definitely agree & slightly agree & slightly disagree & definitely disagree \\
\hline definitely agree & slightly agree & slightly disagree & definitely disagree \\
\hline definitely agree & slightly agree & slightly disagree & definitely disagree \\
\hline definitely agree & slightly agree & slightly disagree & definitely disagree \\
\hline definitely agree & slightly agree & slightly disagree & definitely disagree \\
\hline definitely agree & slightly agree & slightly disagree & definitely disagree \\
\hline definitely agree & slightly agree & slightly disagree & definitely disagree \\
\hline definitely agree & slightly agree & slightly disagree & definitely disagree \\
\hline definitely agree & slightly agree & slightly disagree & definitely disagree \\
\hline definitely agree & slightly agree & slightly disagree & definitely disagree \\
\hline definitely agree & slightly agree & slightly disagree & definitely disagree \\
\hline definitely agree & slightly agree & slightly disagree & definitely disagree \\
\hline definitely agree & slightly agree & slightly disagree & definitely disagree \\
\hline
\end{tabular}


27. I find it easy to "read between the lines" when someone is talking to me.

28. I usually concentrate more on the whole picture, rather than the small details.

29. I am not very good at remembering phone numbers.

30. I don't usually notice small changes in a situation, or a person's appearance.

31. I know how to tell if someone listening to me is getting bored.

32. I find it easy to do more than one thing at once.

33. When I talk on the phone, I'm not sure when it's my tum to speak.

34. I enjoy doing things spontaneously.

35. I am often the last to understand the point of a joke.

36. I find it easy to work out what someone is thinking or feeling just by looking at their face.

37. If there is an interruption, I can switch back to what I was doing very quickly.

38. I am good at social chit-chat.

39. People often tell me that I keep going on and on about the same thing.

40. When I was young, I used to enjoy playing games involving pretending with other children.

41. I like to collect information about categories of things (e.g. types of car, types of bird, types of train, types of plant, etc.).

42. I find it difficult to imagine what it would be like to be someone else.

43. I like to plan any activities I participate in carefully.

44. I enjoy social occasions.

45. I find it difficult to work out people's intentions.

46. New situations make me anxious.

47. I enjoy meeting new people.

48. I am a good diplomat.

49. I am not very good at remembering people's date of birth.

50. I find it very easy to play games with children that involve pretending.

\begin{tabular}{|c|c|c|c|}
\hline definitely agree & slightly agree & slightly disagree & definitely disagree \\
\hline definitely agree & slightly agree & slightly disagree & definitely disagree \\
\hline definitely agree & slightly agree & slightly disagree & definitely disagree \\
\hline definitely agree & slightly agree & slightly disagree & definitely disagree \\
\hline definitely agree & slightly agree & slightly disagree & definitely disagree \\
\hline definitely agree & slightly agree & slightly disagree & definitely disagree \\
\hline definitely agree & slightly agree & slightly disagree & definitely disagree \\
\hline definitely agree & slightly agree & slightly disagree & definitely disagree \\
\hline definitely agree & slightly agree & slightly disagree & definitely disagree \\
\hline definitely agree & slightly agree & slightly disagree & definitely disagree \\
\hline definitely agree & slightly agree & slightly disagree & definitely disagree \\
\hline definitely agree & slightly agree & slightly disagree & definitely disagree \\
\hline definitely agree & slightly agree & slightly disagree & definitely disagree \\
\hline definitely agree & slightly agree & slightly disagree & definitely disagree \\
\hline definitely agree & slightly agree & slightly disagree & definitely disagree \\
\hline definitely agree & slightly agree & slightly disagree & definitely disagree \\
\hline definitely agree & slightly agree & slightly disagree & definitely disagree \\
\hline definitely agree & slightly agree & slightly disagree & definitely disagree \\
\hline definitely agree & slightly agree & slightly disagree & definitely disagree \\
\hline definitely agree & slightly agree & slightly disagree & definitely disagree \\
\hline definitely agree & slightly agree & slightly disagree & definitely disagree \\
\hline definitely agree & slightly agree & slightly disagree & definitely disagree \\
\hline definitely agree & slightly agree & slightly disagree & definitely disagree \\
\hline definitely agree & slightly agree & slightly disagree & definitely disagree \\
\hline
\end{tabular}


Appendix B: Bergen Dichotic Listening Test Score Sheet

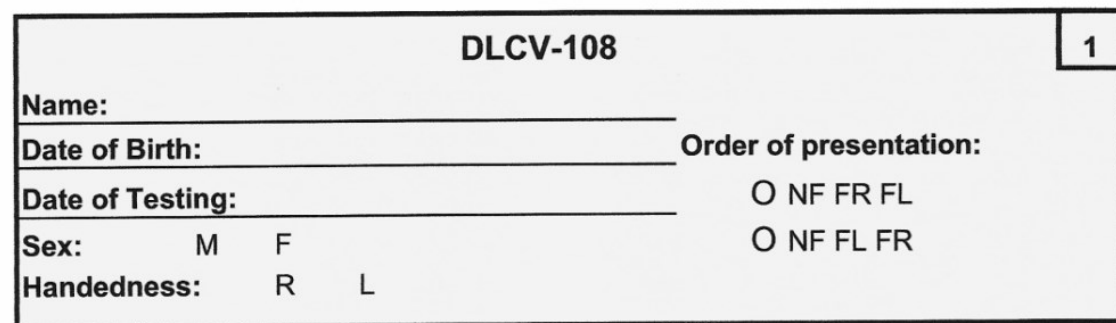

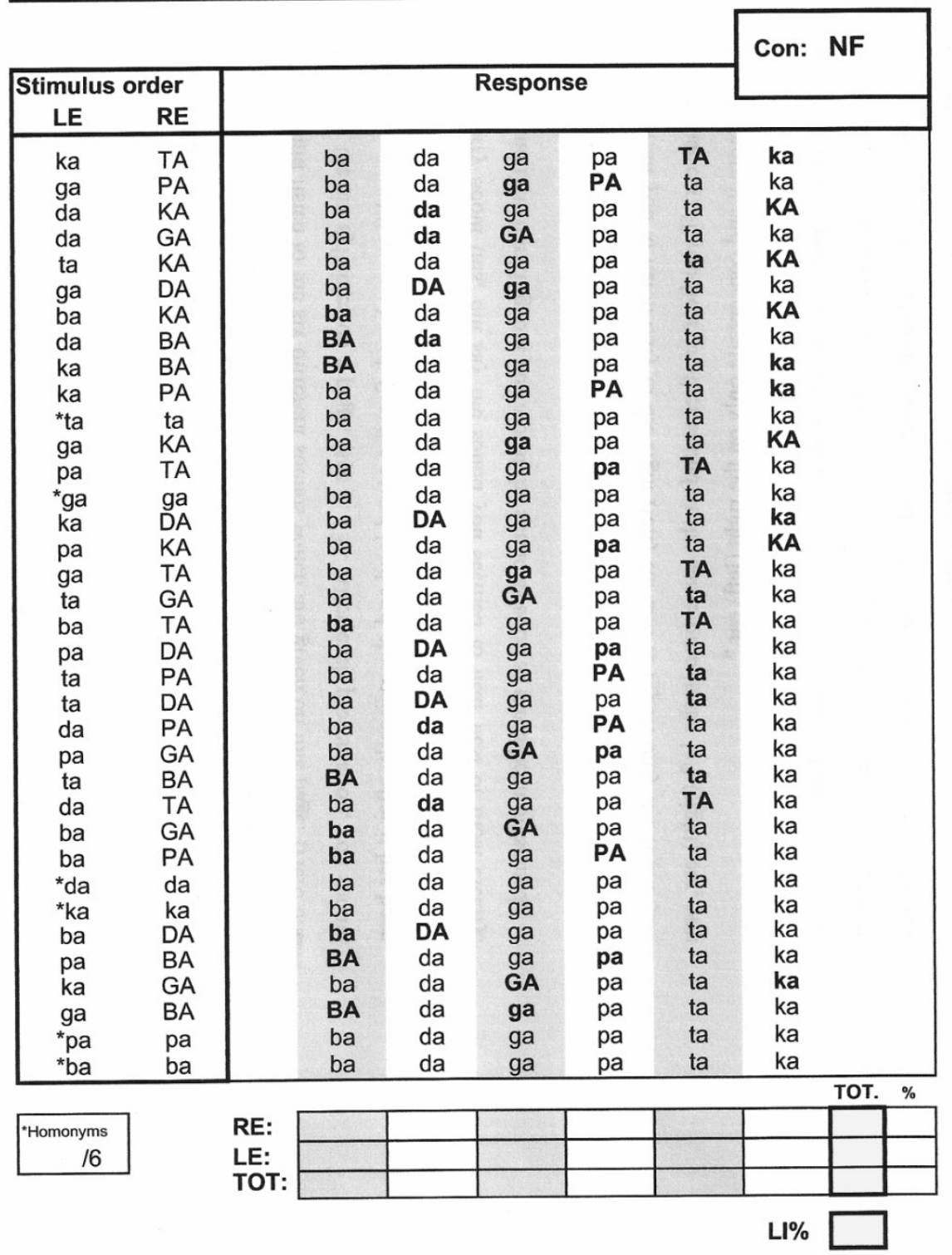




\title{
Appendix C: Bergen Dichotic Listening Test Instructional Paragraph
}

\author{
Instruction Procedure
}

Test subjects (patients) should be instructed in the NF condition as follows: "You should listen to the six different sounds which are given on this page. (Here one can show the six syllables on a page, (see p. 13). After each presentation, you should report the sound that you heard. Say the sound loud and clear directly after it has been presented. Sometimes it will seem as if you hear two different sounds at the same time. Don't worry about this, but say the sound you seemed to hear best or most clearly. Don't spend time thinking, but just repeat the sound as soon as it has been presented."

For the FR (FL) conditions, the test subjects (patients) should be instructed as follows: "Now I want you to listen only to the right (left) ear and to report only the sound you hear in that ear. If you hear another sound at the same time in the left (right) ear, you should ignore it and concentrate only on the right (left) ear."

Here one should point to the right (left) ear in order to show which side the test subject should reproduce from. This is especially important in the testing of children and of patients with weakened cognitive/spatial functions. For all conditions the test subject should give only one response per presentation.

\section{Scoring and Data Evaluation}

The scoring of answers is based on the number of correctly reproduced syllables presented to the right, or respectively the left, ear. It is usual to calculate percentage scores for the right ear (RE \%) and for the left ear (LE \%) on the basis of the number of correct answers in accordance with the formulae: 


\section{Appendix D: Waterloo Handedness Questionnaire}

Instructions: Answer each of the following questions as best you can. If you always use one hand to perform the described activity, circle Ra or La (for right always or left always). If you usually use one hand circle $\mathrm{Ru}$ or $\mathrm{Lu}$ (for usually right or usually left), as appropriate. If you use both hands equally often, circle Eq.

Do not simply circle one answer for all questions, but imagine yourself performing each activity in turn, then mark the appropriate answer. If necessary, stop and pantomime the activity.

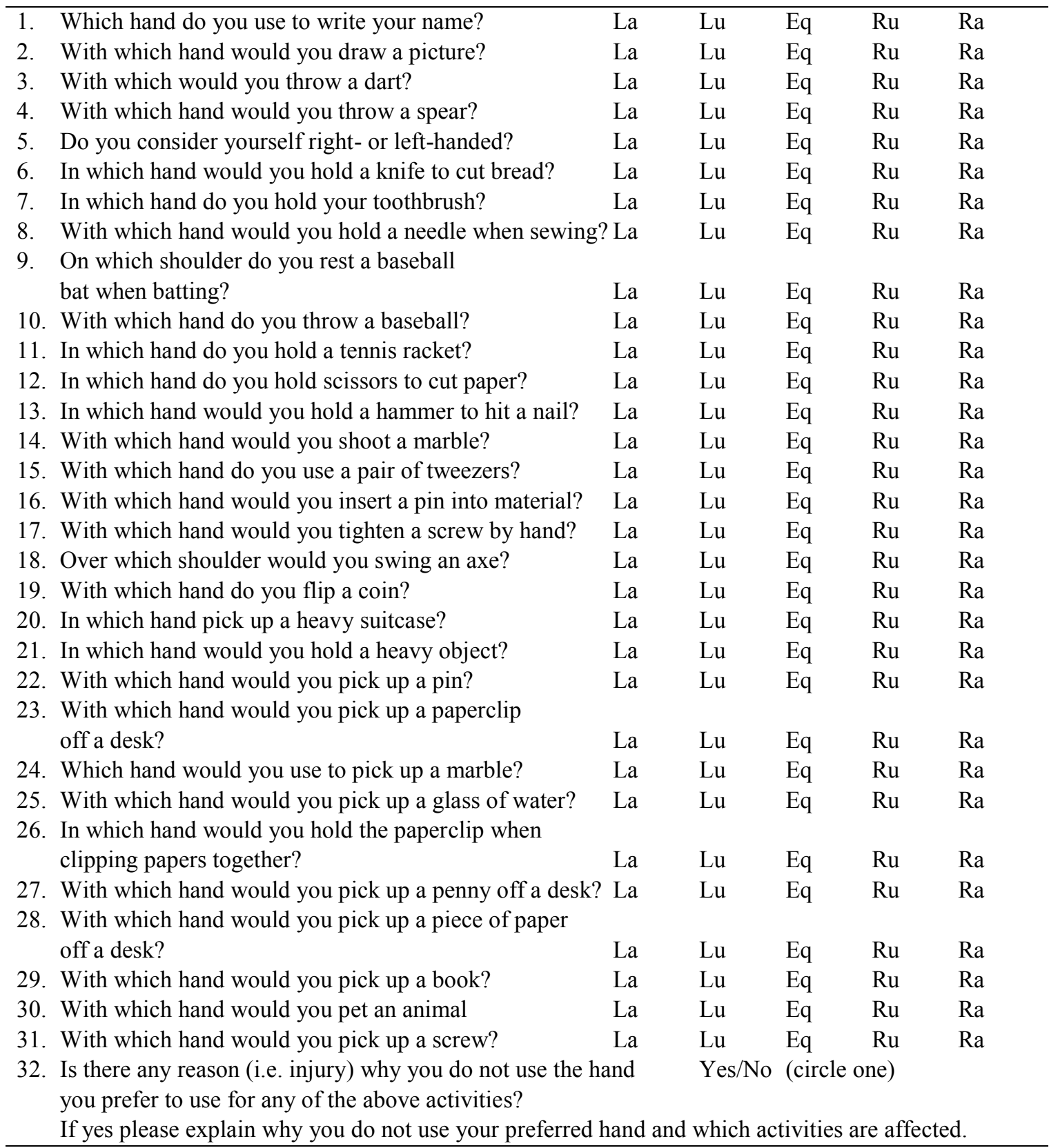


Appendix E: Rhythmic Tapping Task Instructional Window

\section{Ready to start trial \#1}

\section{Instructions}

Listen to the beat and tap to the same beat with the index finger of your RIGHT hand only. Try to synchronize your tapping with the beat as accurately

and rhytmically as possible. After 15s, the beat will stop and

you will continue to tap at the same rate and rhythm until this trial is over.

Press your LEFT or RIGHT key to start the trial. 


\section{Appendix F: Additional Information Questionnaire}

Additional information Questionnaire

Age:

Gender: $M / F$

Major:

GPA:

Please indicate if you have been diagnosed with any of the following conditions (formal diagnosis by a clinician).
a. Autism
b. Asperger Syndrome
c. Dyslexia
d. ADHD

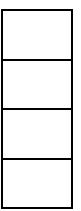

Please indicate if you have been diagnosed with any of the following conditions (formal diagnosis by a medical doctor).

a. Multiple Concussions (3 or more)

b. Fragile X Syndrome 


\section{Appendix G: Five-Factor AQ Item Loadings}

Item loadings of the Autism Quotient five-factor solution with promax rotation.

\begin{tabular}{|c|c|c|c|c|c|}
\hline \multirow[t]{2}{*}{ Autism Quotient Items } & \multicolumn{5}{|l|}{ Factor } \\
\hline & 1 & 2 & 3 & 4 & 5 \\
\hline \multicolumn{6}{|l|}{ Social Skill Scale } \\
\hline $\begin{array}{l}\text { I prefer to do things with others rather than on } \\
\text { my own. }\end{array}$ & -.323 & -.182 & .111 & .269 & -.312 \\
\hline I find social situations easy. & .710 & .039 & -.155 & .053 & .107 \\
\hline I would rather go to a library than a party. & .504 & .241 & -.073 & -.267 & .008 \\
\hline $\begin{array}{l}\text { I find myself drawn more strongly to people } \\
\text { than to things. }\end{array}$ & .590 & .319 & -.147 & -.178 & .018 \\
\hline I find it hard to make new friends. & .721 & .054 & -.020 & -.071 & -.134 \\
\hline $\begin{array}{l}\text { I find it easy to work out what someone is } \\
\text { thinking or feeling just by looking at their } \\
\text { face. }\end{array}$ & .258 & -.170 & -.253 & .346 & -.034 \\
\hline I enjoy social occasions. & .599 & .177 & .165 & -.293 & .275 \\
\hline $\begin{array}{l}\text { I find it difficult to work out people's } \\
\text { intentions. }\end{array}$ & .345 & -.198 & -.045 & .191 & -.315 \\
\hline I enjoy meeting new people. & .534 & .176 & -.101 & -.179 & .018 \\
\hline I am a good diplomat. & .267 & -.113 & .092 & .117 & -.024 \\
\hline \multicolumn{6}{|l|}{ Attention Switching Scale } \\
\hline $\begin{array}{l}\text { I prefer to do things the same way over and } \\
\text { over again. }\end{array}$ & -.323 & -.182 & .111 & .269 & -.312 \\
\hline $\begin{array}{l}\text { I frequently get so strongly absorbed in one } \\
\text { thing that I lose sight of other things. }\end{array}$ & .444 & -.097 & .110 & -.144 & -.343 \\
\hline $\begin{array}{l}\text { In a social group, I can easily keep track of } \\
\text { several different people's conversations. }\end{array}$ & .293 & -.352 & -.207 & .086 & .031 \\
\hline $\begin{array}{l}\text { I tend to have very strong interests, which I get } \\
\text { upset about if I can't pursue. }\end{array}$ & .259 & .288 & .353 & .086 & -.144 \\
\hline $\begin{array}{l}\text { It does not upset me if my daily routine is } \\
\text { disturbed. }\end{array}$ & .285 & -.385 & .004 & .176 & .212 \\
\hline I find it easy to do more than one thing at once. & .296 & -.233 & -.264 & .209 & -.082 \\
\hline I enjoy doing things spontaneously. & .481 & -.284 & -.264 & .198 & .246 \\
\hline $\begin{array}{l}\text { If there is an interruption, I can switch back to } \\
\text { what I was doing very quickly. }\end{array}$ & .285 & -.257 & -.194 & .200 & -.066 \\
\hline $\begin{array}{l}\text { I like to plan any activities I participate in } \\
\text { carefully. }\end{array}$ & .247 & -.074 & .163 & .175 & .455 \\
\hline New situations make me anxious. & .474 & -.254 & -.013 & -.059 & -.251 \\
\hline \multicolumn{6}{|l|}{ Attention to Detail Scale } \\
\hline I often notice small sounds when others do not. & .107 & .425 & -.182 & .077 & .235 \\
\hline $\begin{array}{l}\text { I usually notice car number plates or similar } \\
\text { strings of information. }\end{array}$ & -.006 & .442 & -.237 & .378 & .117 \\
\hline I am fascinated by dates. & .134 & .446 & .078 & .283 & .077 \\
\hline
\end{tabular}


I tend to notice details that others do not.

I am fascinated by numbers.

I notice patterns in things all the time.

I usually concentrate more on the whole picture rather than the small details.

I am not very good at remembering phone numbers.

I don't usually notice small changes in a situation or a person's appearance.

I am not very good at remembering people's date of birth.

Communication Scale

Other people frequently tell me that what I've said is impolite, even though I think it is polite.

I enjoy social chit-chat.

When I talk, it isn't always easy for others to get a word in edgewise.

I frequently find that I don't know how to keep a conversation going.

I find it easy to "read between the lines" when someone is talking to me.

I know how to tell if someone listening to me is getting bored.

When I talk on the phone, I'm not sure when it's my turn to speak.

I am often the last to understand the point of a joke.

I am good at social chit-chat.

People often tell me that I keep going on and on about the same thing.

Imagination Scale

If I try to imagine something, I find it very easy to create a picture in my mind.

When I'm reading a story, I can easily imagine what the characters might look like.

I find making up stories easy.

When I'm reading a story, I find it difficult to work out the character's intentions.

I don't particularly enjoy reading fiction.

I would rather go to the theatre than a museum.

When I was young, I used to enjoy playing games involving pretending with other children.

$\begin{array}{rrrrr}.059 & .363 & -.181 & .273 & .146 \\ .089 & .535 & .066 & .119 & .103 \\ .130 & .564 & .187 & .053 & -.174 \\ .197 & .201 & .043 & .387 & .009 \\ & & & & \\ -.061 & .400 & .081 & .269 & .110 \\ -.081 & .231 & -.308 & .399 & .028 \\ & & & & \\ -.187 & .303 & -.060 & .380 & -.014\end{array}$

$\begin{array}{lllll}.177 & .235 & .349 & -.189 & -.295\end{array}$

$\begin{array}{lllll}.649 & .216 & -.133 & -.267 & .195\end{array}$

$\begin{array}{lllll}.202 & .100 & .402 & .181 & -.033\end{array}$

$\begin{array}{lllll}.560 & -.071 & .072 & .018 & -.150\end{array}$

$\begin{array}{lllll}.146 & -.139 & -.137 & .293 & -.078\end{array}$

$\begin{array}{lllll}.109 & .059 & -.017 & .085 & -.155\end{array}$

$\begin{array}{lllll}.423 & -.157 & .043 & .091 & -.298\end{array}$

$\begin{array}{lllll}.399 & -.293 & .126 & .220 & -.135\end{array}$

$\begin{array}{lllll}.755 & .023 & -.035 & -.205 & .086\end{array}$

$\begin{array}{lllll}.234 & -.123 & .329 & .154 & -.267\end{array}$

$\begin{array}{rrrrr}-.065 & -.102 & . \mathbf{4 6 7} & -.232 & .367 \\ & & & & \\ .014 & -.150 & . \mathbf{4 4 7} & .059 & .048 \\ & & & & \\ .259 & -.278 & .121 & .226 & \mathbf{. 4 9 8} \\ .130 & .064 & .358 & .278 & -.270 \\ & & & & \\ .007 & .044 & \mathbf{. 5 2 4} & .311 & .051 \\ . \mathbf{4 0 1} & .180 & \mathbf{- . 0 2 5} & -.077 & -.093 \\ .043 & -.030 & \mathbf{. 4 5 9} & .032 & .264\end{array}$


I like to collect information about categories of things (e.g., types of car, types of bird,

$\begin{array}{lllll}.231 & \mathbf{4 0 2} & .072 & .102 & -.241\end{array}$ types of train, types of plant, etc.)

I find it difficult to imagine what it would be like to be someone else.

$\begin{array}{llllll}\text { I find it very easy to play games with children } & .249 & -.219 & .331 & .097 & .329\end{array}$ that involve pretending.

Proportion of variance by factor $\%$

\begin{tabular}{lllll}
12.27 & 6.71 & 4.93 & 4.67 & 4.13 \\
\hline
\end{tabular}

Note. All items with loadings $\geq 0.40$ (the criteria used by Austin, 2005) are bolded. Items for each of the five domains are listed to be consistent with the initial proposed fivefactor structure 


\section{Appendix H: Three-Factor AQ Item Loadings}

Item loadings of the Autism Quotient three-factor solution with promax rotation.

\begin{tabular}{|c|c|c|c|}
\hline \multirow[t]{2}{*}{ Three-factor Autism Quotient based on Austin (2005) } & \multicolumn{3}{|l|}{ Factor } \\
\hline & 1 & 2 & 3 \\
\hline \multicolumn{4}{|l|}{ Social Skills } \\
\hline I am good at social chit-chat. & .765 & -.112 & -.094 \\
\hline I find social situations easy. & .720 & .003 & .128 \\
\hline I enjoy social occasions. & 671 & .114 & -.190 \\
\hline I enjoy social chit-chat. & .717 & .043 & -.065 \\
\hline I frequently find that I don't know how to keep a conversation going. & .557 & -.182 & -.085 \\
\hline I enjoy meeting new people. & .593 & .120 & -.160 \\
\hline I find it hard to make new friends. & .729 & -.060 & -.107 \\
\hline $\begin{array}{l}\text { When I was young, I used to enjoy playing games involving } \\
\text { pretending with other children. }\end{array}$ & .067 & -.064 & -.111 \\
\hline I find myself drawn more strongly to people than to things. & .645 & .219 & -.065 \\
\hline I enjoy doing things spontaneously. & .439 & -.352 & .433 \\
\hline $\begin{array}{l}\text { I find it very easy to play games with children that involve } \\
\text { pretending. }\end{array}$ & .202 & -.323 & .027 \\
\hline I would rather go to a library than a party. & .563 & .126 & -.058 \\
\hline \multicolumn{4}{|l|}{ Detail/patterns } \\
\hline I notice patterns in things all the & .200 & .588 & .040 \\
\hline I usually notice car number plates or similar strings of information. & .041 & .485 & .491 \\
\hline I am fascinated by numbers. & .167 & .580 & .043 \\
\hline I am fascinated by dates. & .178 & .386 & .089 \\
\hline s that others do not. & .117 & .404 & .449 \\
\hline in carefully. & .231 & -.166 & .300 \\
\hline I often notice small sounds when others do not. & .187 & .451 & .303 \\
\hline It does not upset me if my daily routine is disturbed. & .217 & -.397 & .392 \\
\hline \multicolumn{4}{|l|}{ Communication/mindreading } \\
\hline People often tell me that I keep going on and on about the same thing. & .155 & -.264 & -.064 \\
\hline $\begin{array}{l}\text { When I'm reading a story, I find it difficult to work out the } \\
\text { character's intentions. }\end{array}$ & .110 & .058 & -.221 \\
\hline I find it difficult to work out people's intentions. & .267 & -.224 & -.135 \\
\hline I am often the last to understand the point of a joke. & .321 & -.387 & .022 \\
\hline $\begin{array}{l}\text { Other people frequently tell me that what I've said is impolite, even } \\
\text { though I think it is polite. }\end{array}$ & .175 & .252 & -.524 \\
\hline $\begin{array}{l}\text { If there is an interruption, I can switch back to what I was doing very } \\
\text { quickly. }\end{array}$ & .225 & -.308 & .460 \\
\hline Proportion of variance by factor $\%$ & 18.54 & 9.32 & 6.41 \\
\hline
\end{tabular}

Note. All items with loadings $\geq 0.40$ are bolded. 